Review

\title{
Modulation of Autophagy-Like Processes by Tumor Viruses
}

\author{
Hildegard I. D. Mack * and Karl Munger * \\ Division of Infectious Diseases, Brigham and Women's Hospital, Department of Medicine, \\ Harvard Medical School, Boston, MA 02115, USA \\ * Authors to whom correspondence should be addressed; \\ E-Mails: hmack@rics.bwh.harvard.edu (H.I.D.M.); kmunger@rics.bwh.harvard.edu (K.M.); \\ Tel.: +1-617-525-4282; Fax: +1-617-525-4283.
}

Received: 16 May 2012; in revised form: 13 June 2012 / Accepted: 14 June 2012 /

Published: 25 June 2012

\begin{abstract}
Autophagy is an intracellular degradation pathway for long-lived proteins and organelles. This process is activated above basal levels upon cell intrinsic or environmental stress and dysregulation of autophagy has been linked to various human diseases, including those caused by viral infection. Many viruses have evolved strategies to directly interfere with autophagy, presumably to facilitate their replication or to escape immune detection. However, in some cases, modulation of autophagy appears to be a consequence of the virus disturbing the cell's metabolic signaling networks. Here, we summarize recent advances in research at the interface of autophagy and viral infection, paying special attention to strategies that human tumor viruses have evolved.
\end{abstract}

Keywords: autophagy; cancer; Epstein-Barr virus; hepatitis B virus; hepatitis C virus; human papillomavirus; human T-lymphotropic virus 1; Kaposi's sarcoma-associated herpesvirus; Merkel cell polyomavirus

\section{Introduction}

\subsection{Human Oncogenic Viruses}

Viruses are intracellular parasites that strictly depend on a host to replicate. Thus, after entry, they reprogram their host cells to meet their needs. For the host, the consequences of viral infection span a wide range from being asymptomatic to causing deadly disease. Approximately $10-15 \%$ of human 
cancers are associated with viral infections [1]. Despite this substantial number, the list of human viruses that are clearly involved in the etiology of human tumors is rather short [2]. The first human tumor viruses to be identified is Epstein-Barr Virus (EBV) that has been linked to Hodgkin's lymphoma, Burkitt's lymphoma, nasopharyngeal carcinoma as well as other hematological malignancies in immunosuppressed individuals [3]. Hepatitis $\mathrm{B}(\mathrm{HBV})$ and $\mathrm{C}(\mathrm{HCV})$ viruses have been linked to hepatocellular carcinoma (HCC) [4], human papillomaviruses (HPVs) to cervical, anal, vulvar, vaginal, penile and oropharyngeal cancers as well as to squamous cell skin carcinomas in immunosuppressed patients [5], and the human T-lymphotropic virus 1 (HTLV-1) has been linked to adult T-cell leukemia (ATL) [6]. More recently identified human oncogenic viruses include Kaposi's sarcoma-associated herpesvirus (KSHV) that causes Kaposi's sarcoma, primary effusion lymphoma (PEL) and Castleman's disease [7] and the Merkel cell polyomavirus (MCPyV) that has been linked to a rare but highly lethal skin cancer, Merkel cell carcinoma (MCC) [2] (Table 1). In addition to the viruses listed above, a number of other viruses have been reported to contribute to human cancers but these associations remain to be confirmed [8]. One interesting emerging candidate is the human cytomegalovirus (HCMV), which may modulate the carcinogenic phenotype of cancers, in particular glioblastoma. While HCMV encodes multiple proteins that can subvert the activities of cellular tumor suppressors, the clinical significance of the presence of HCMV sequences in these tumors remains controversial [9]. With the advent of deep sequencing, one might expect that viral sequences and/or transcripts will be detected in even more cancer types but the mere discovery of viral sequences in a tumor does not imply a causative relationship. It is worth noting that while infections with one of the established human tumor viruses is associated with a majority or at least a significant percentage of the respective cancers, some of these cancers can also arise without viral infection.

Although human tumor viruses comprise a diverse group of viruses (Table 1), most of them share the ability to establish long-term latent or persistent infections. In this state, the viral genome is maintained as an episomal element or as an integrated genome copy within a host chromosome, and is replicated along with the host cellular genome by the host's DNA replication machinery. Structural viral proteins required for virion formation are not, or at least not abundantly synthesized during latency [2]. This most likely decreases the vulnerability of virally infected cells for elimination by the immune system.

To ensure viral survival and propagation, progeny virus needs to be generated and the host cell has to produce the necessary enzymes and metabolites. Therefore, many tumor viruses encode proteins that promote cell cycle entry, counteract programmed cell death, subvert cellular differentiation and/or interfere with immune signaling [10]. However, virtually all of the cellular pathways targeted by these viruses can contribute to carcinogenesis. In some cases, particularly with HPV associated cervical carcinoma and MCPyV induced Merkel cell carcinoma, viral oncogenesis represents a consequence of a non-productive infection, i.e., the expression of viral proteins in the absence of the viral life cycle and many of these tumors only express a subset of viral proteins or fragments thereof from integrated viral subgenomes [11]. 
Table 1. Human tumor viruses, their associated cancers, and mechanisms of autophagy modulation.

\begin{tabular}{|c|c|}
\hline $\begin{array}{l}\text { Associated } \\
\text { cancer types }\end{array}$ & $\begin{array}{l}\text { Mechanism of interference with autophagy and/or } \\
\text { autophagy-regulating pathways }\end{array}$ \\
\hline \multicolumn{2}{|c|}{ Epstein-Barr virus (EBV) Herpesviridae } \\
\hline $\begin{array}{l}\text { Burkitt's and Hodgkin- } \\
\text { and non-Hodgkin } \\
\text { lymphomas, } \\
\text { nasopharyngeal } \\
\text { carcinoma, } \\
\text { lymphoproliferative } \\
\text { diseases }\end{array}$ & 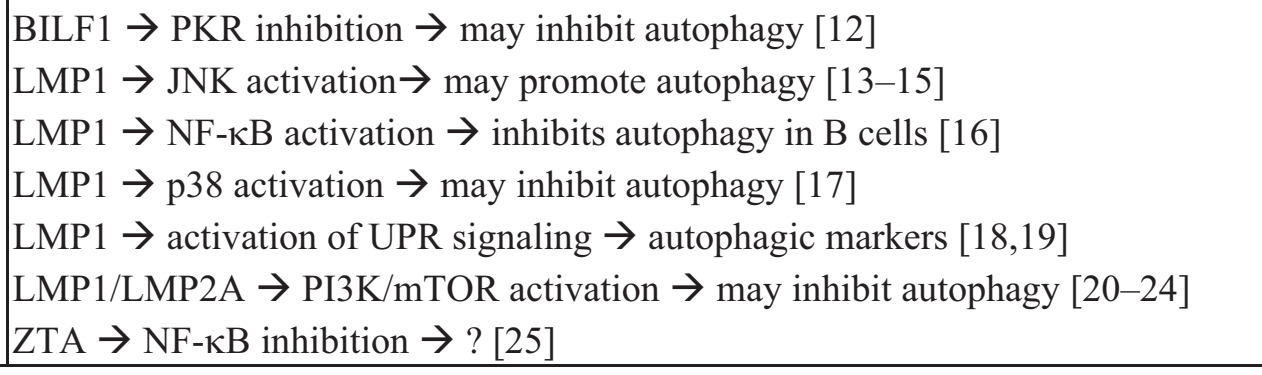 \\
\hline \multicolumn{2}{|c|}{ Hepatitis B virus (HBV) Hepadnaviridae } \\
\hline $\begin{array}{l}\text { Hepatocellular } \\
\text { carcinoma }\end{array}$ & 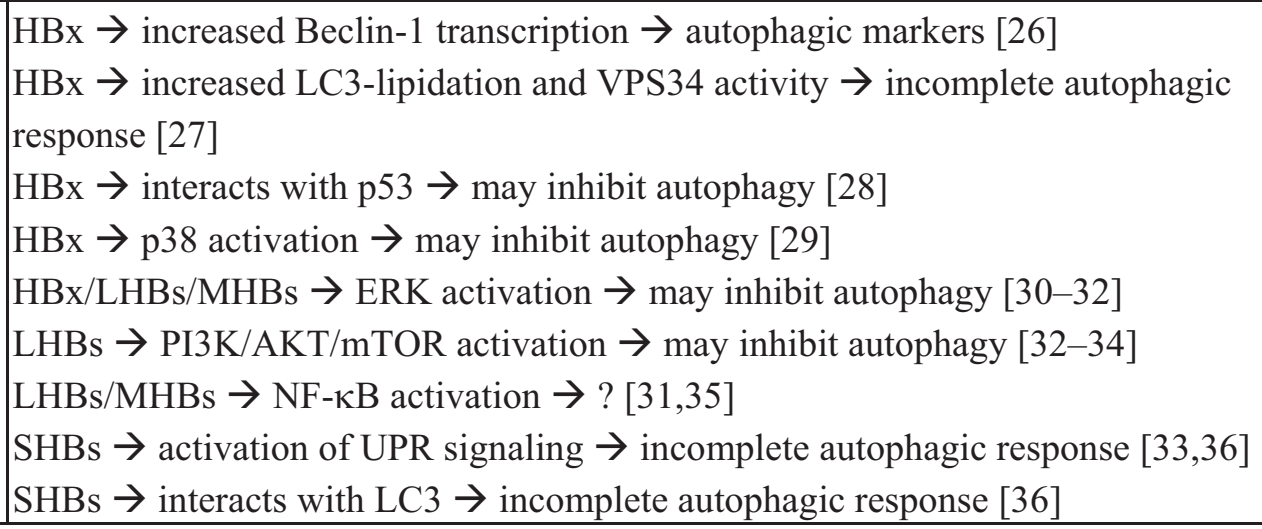 \\
\hline \multicolumn{2}{|c|}{ Hepatitis C virus (HCV) Flaviviridae } \\
\hline $\begin{array}{l}\text { Hepatocellular } \\
\text { carcinoma }\end{array}$ & 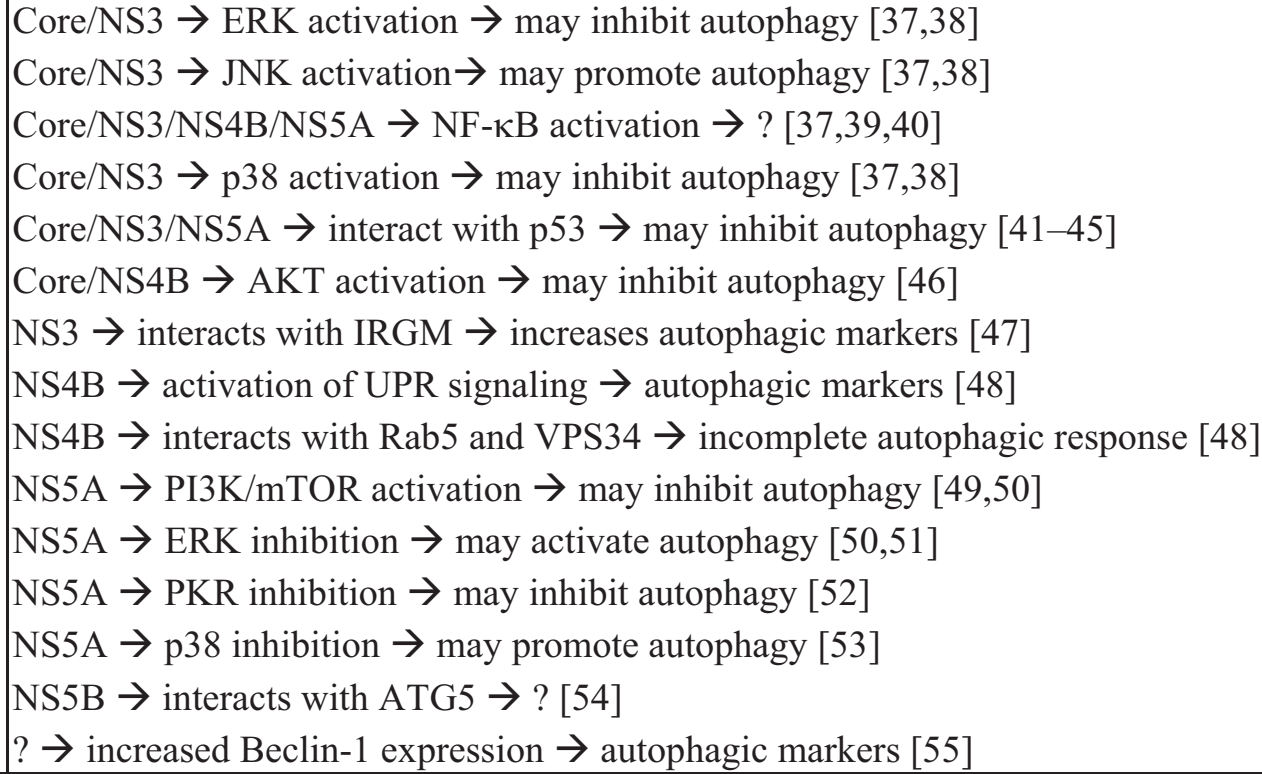 \\
\hline
\end{tabular}


Table 1. Cont.

\begin{tabular}{|c|c|}
\hline $\begin{array}{l}\text { Associated } \\
\text { cancer types }\end{array}$ & $\begin{array}{l}\text { Mechanism of interference with autophagy and/or } \\
\text { autophagy-regulating pathways }\end{array}$ \\
\hline \multicolumn{2}{|c|}{ Human papillomavirus, high-risk types (HPV) Papillomaviridae } \\
\hline $\begin{array}{l}\text { Cervical, anal and } \\
\text { penile cancers, head } \\
\text { and neck cancers }\end{array}$ & $\begin{array}{l}\text { E5 } \rightarrow \text { p38 activation } \rightarrow \text { may inhibit autophagy [56] } \\
\text { E5/E6/E7 } \rightarrow \text { inhibit XBP1-splicing under basal conditions } \rightarrow \text { ? [57] } \\
\text { E6 } \rightarrow \text { sustained AKT/mTORC1 activity } \rightarrow \text { may inhibit autophagy }[58,59] \\
\text { E6 } \rightarrow \text { inhibits p53 } \rightarrow \text { may inhibit autophagy [60] } \\
\text { E6/E7 } \rightarrow \text { ERK activation } \rightarrow \text { may inhibit autophagy [61] } \\
\text { E7 } \rightarrow \text { AKT activation } \rightarrow \text { may inhibit autophagy }[62,63] \\
\text { E7 } \rightarrow \text { NF-אB inhibition } \rightarrow \text { ? [64-66] } \\
\text { E7 } \rightarrow \text { JNK inhibition } \rightarrow \text { may inhibit autophagy [67] } \\
\text { E7 } \rightarrow ? \rightarrow \text { autophagic markers [68] }\end{array}$ \\
\hline \multicolumn{2}{|c|}{ Human T-lymphotropic virus (HTLV-1) Retroviridae } \\
\hline Adult T-cell leukemia & $\begin{array}{l}\text { Tax } \rightarrow \text { JNK activation } \rightarrow \text { may promote autophagy [69] } \\
\text { Tax } \rightarrow \text { sustained AKT/mTORC1 activity } \rightarrow \text { may inhibit autophagy [70,71] } \\
\text { Tax } \rightarrow \text { p38 activation } \rightarrow \text { may inhibit autophagy [69] } \\
\text { Tax } \rightarrow \text { activation of UPR signaling } \rightarrow \text { may promote autophagy [72] } \\
\text { Tax } \rightarrow \text { inhibits p53 } \rightarrow \text { may inhibit autophagy [73] } \\
\text { Tax }+ \text { HBZ } \rightarrow \text { NF-אB activation } \rightarrow \text { ? [74-77] }\end{array}$ \\
\hline \multicolumn{2}{|c|}{ Kaposi's sarcoma associated herpesvirus (KSHV) Herpesviridae } \\
\hline $\begin{array}{l}\text { Kaposi's sarcoma, } \\
\text { pleural effusion } \\
\text { lymphoma, } \\
\text { multicentric } \\
\text { Castleman's disease }\end{array}$ & $\begin{array}{l}\text { K1 } \rightarrow \text { PI3K/AKT/mTOR activation } \rightarrow \text { may inhibit autophagy }[78-80] \\
\text { K15 } \rightarrow \text { ERK activation } \rightarrow \text { may inhibit autophagy }[81] \\
\text { K15 } \rightarrow \text { p38 activation } \rightarrow \text { may inhibit autophagy }[81] \\
\text { LANA } \rightarrow \text { inhibits p53 } \rightarrow \text { may inhibit autophagy }[82] \\
\text { ORF45 } \rightarrow \text { sustained ERK/RSK activity } \rightarrow \text { autophagy }[83,84] \\
\text { ORF49 } \rightarrow \text { JNK activation } \rightarrow \text { may promote autophagy }[85] \\
\text { ORF49/vGPCR } \rightarrow \text { p38 activation } \rightarrow \text { may inhibit autophagy }[85,86] \\
\text { RTA } \rightarrow \text { ? } \rightarrow \text { increased autophagy [87] } \\
\text { vBCL-2 } \rightarrow \text { interacts with Beclin-1 } \rightarrow \text { autophagy inhibition }[88,89] \\
\text { vFLIP } \rightarrow \text { interacts with ATG3 } \rightarrow \text { autophagy inhibition }[90] \\
\text { vFLIP/K15/ORF75/miR-K1/vGPCR7/vIRF3 } \rightarrow \text { NF-kB activation } \rightarrow ?[81,91-96] \\
\text { vGPCR } \rightarrow \text { PI3K } \gamma / \text { mTORC1 activation } \rightarrow \text { may inhibit autophagy [97] } \\
\text { vIRF2/vIRF3 } \rightarrow \text { PKR inhibition } \rightarrow \text { may inhibit autophagy }[98,99] \\
\text { vIRF3 } \rightarrow \text { NF-KB inhibition } \rightarrow \text { ? [93,100] }\end{array}$ \\
\hline \multicolumn{2}{|c|}{ Merkel cell polyomavirus (MCPyV) Polyomaviridae } \\
\hline Merkel cell carcinoma & Small $\mathrm{T} \rightarrow$ mTORC1 activation $\rightarrow$ may inhibit autophagy [75] \\
\hline
\end{tabular}

The table lists established human tumor viruses, their associated malignancies and the autophagy-related proteins and autophagy-regulating signaling pathways they modulate. Note that in many studies, an effect on autophagy has not been explicitly investigated or conclusively and comprehensively validated [101]. With regard to the current literature, it is difficult to predict effects of NF-kB activation on autophagy. ERK, JNK and p38 modulate or have been suggested to modulate autophagy via pathways other than NF-kB, and the predictions listed in this table are based on these mechanisms [102-104]. 


\subsection{Autophagy—Basic Function and Role in Human Disease}

Autophagy is a key homeostatic process conserved across all eukaryotic cells. The term literally translated means "self-eating" and describes a degradation pathway for intracellular structures via the lysosomal compartment. Although several mechanistically distinct forms of autophagy are distinguished (macro-, micro- and chaperone-mediated autophagy (reviewed in [105]) "autophagy" is commonly (and also for the purpose of this review) used synonymously with macroautophagy, the most widely studied subtype. (Macro)autophagy is characterized by formation of large, double membraned vesicles, so called autophagosomes, that sequester bulk portions of cytoplasm and, after closure, fuse with lysosomes so that the cargo can be degraded by lysosomal enzymes. This process takes place at a low basal level under physiologic conditions and facilitates turnover of long-lived proteins and organelles. However, upon exposure to environmental and endogenous stressors, such as nutrient- and growth factor deprivation, hypoxia, high temperature or organelle damage, autophagy is upregulated. Autophagy primarily represents a pro-survival mechanism, but in complex multicellular organisms, it serves additional purposes, including a role in adaptive and innate immunity. Autophagy has also been linked to programmed cell death, however, it is controversial at present whether the phenomenon of autophagic cell death actually exists [106]. Deregulation of autophagy has been implicated in a variety of human diseases including neurodegenerative diseases, cardiac disease, liver disease, myopathies, cancer and bacterial and viral infection [105]. Human tumors associated with the viruses mentioned above represent the interface between cancer and infectious diseases. Thus, autophagy may play an especially multifaceted role in virus-associated malignancies since it has proand anti-tumorigenic as well as pro- and anti-viral functions.

\subsection{Components of the Mammalian Autophagy Machinery}

On the molecular level, autophagy is mediated by the so-called Atg-genes/proteins, most of which were originally identified in genetic screens in the yeast Saccharomyces cerevisiae [107]. Of the 35 Atg-proteins described to date, 21 function in all autophagy-related processes or specifically in non-selective bulk macroautophagy, while 14 Atg-proteins are required only for specialized subtypes such as pexophagy or mitophagy or the yeast-specific cytoplasm to vacuole targeting (Cvt) pathway [108-112]. Mammalian cells possess structural or functional homologs for at least 16 of the 21 "core" Atg-proteins and a few vertebrate- or mammalian-specific autophagy factors such as Ambra-1 or ATG101 [108,113-115]. An overview of the autophagy pathway in mammalian cells is presented in Figure 1.

In this review, we summarize our current knowledge on the particular strategies that human tumor viruses have evolved to interface with the host cell autophagy machinery and with autophagyregulating signaling pathways. We first examine the role of autophagy on the viral life cycle and subsequently describe mechanisms by which tumor viruses modulate this process. Yet, it should be emphasized that most of the virus - host cell interactions discussed below are not specific to human tumor viruses but have been described for non-tumorigenic viruses as well. 
Figure 1. Schematic representation of the autophagy pathway in mammalian cells and interactions with viral proteins.

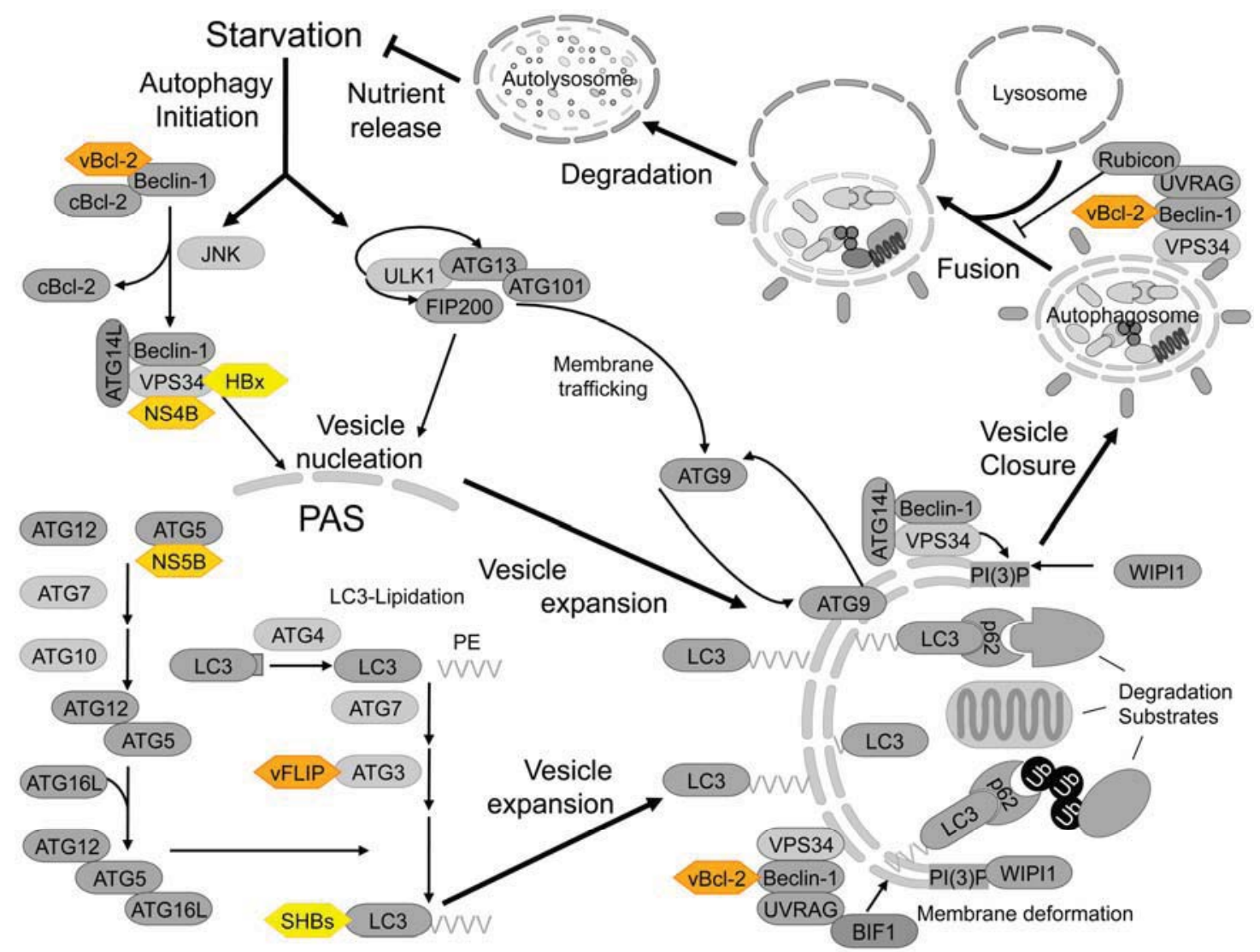

HBV HCV HPV HTLV-1 KSHV MCPYV

The Atg-proteins can be grouped into four (or into six, according to other authors, e.g., [116]) functional modules that mediate the major steps of autophagy [117]: (1) An autophagy initiation complex consisting of the Serine/Threonine kinase ULK1 (or its close relative ULK2), and the regulatory proteins ATG13, focal adhesion kinase family interacting protein of $200 \mathrm{kD}$ (FIP200) and ATG101 [116]; (2) A class III phosphatidylinositol 3-kinase (PI3K), VPS34, which, in cooperation with its interaction partners, facilitates vesicle nucleation. There are at least three biochemically and functionally distinct class III PI3K-complexes in mammalian cells, which share a common core comprising VPS34 itself and ATG6/Beclin-1 as well as p150 and Ambra-1 (omitted for clarity). The first complex comprises the core and ATG14L/Barkor and mediates autophagosome nucleation. The second complex, containing the core and UV irradiation resistance associated protein (UVRAG) may be involved in autophagosome extension and/or other endosomal pathways [118]. The third complex, in which the core is associated with UVRAG and RUN domain and cysteine-rich domain containing Beclin-1 interacting protein (Rubicon) inhibits autophagosome and endosome maturation; (3) Two interconnected ubiquitin-like conjugation systems involved in autophagosome expansion and cargo recruitment. In these systems, the E1- and E2-like enzymes, ATG7 and ATG10, respectively, facilitate conjugation of the ubiquitin-like protein ATG12 to ATG5. This ATG5-ATG12 conjugate is localized to the expanding autophagosomal membrane by ATG16L and potentially serves as the E3-ligase in the second conjugation system, which facilitates lipidation of the peripheral membrane protein LC3. Conjugation of LC3 further requires proteolytic processing by ATG4, as well as the E1-like enzyme ATG7 and another E2-like enzyme, ATG3 [117]. (4) A membrane trafficking and recycling system whose components are still poorly characterized functionally and include WD repeat domain phosphoinositideinteracting protein 1 (WIPI1), which binds phosphatidylinositol-3-phosphate (the product of the VPS34-lipid 
kinase reaction) and the putative membrane carrier protein ATG9 as well as another transmembrane protein, VMP1, and ATG2 (omitted for clarity) [117]. Some substrates are marked for autophagic degradation by ubiquitination, and both ubiquitinated and non-ubiquitinated cargo can be recruited to the autophagosome by LC3-interacting adaptor proteins such as p62/sequestosome 1 [119]. Autophagic adaptors are especially important in selective forms autophagy and may also play a role in xenophagy of viral proteins [120]. Viral proteins that have been reported to physically interact with components of the autophagy machinery are depicted in this schematic drawing. Please note that upstream signaling pathways that target the ULK1autophagy initiation complex or one of the other Atg-proteins and viral proteins interfering with them were omitted from this figure for clarity but are shown in detail in Figures 3-5. Some of the interactions of viral proteins with host cell autophagy-factors may require further experimental validation (see main text). Light grey rounded rectangles - host cell proteins with enzymatic activity; dark grey rounded rectangles - other host cell proteins; colored hexagons_-viral proteins; $\rightarrow$ : activation; to $\perp$ : inhibition.

\section{Benefits of Autophagy Modulation on the Viral Life Cycle}

As with viral reprogramming of the host cell in general, viral interference with autophagy primarily aims to promote the viral life cycle. This includes avoiding detection by the immune system and creating a cellular environment favorable for viral replication. Autophagy is increasingly recognized as an important part of both innate and adaptive immune responses, which pathogens have to escape in order to successfully establish and sustain an infection [121]. This clearly provides a rationale for viruses to block autophagy. Yet, with regard to viral replication, the autophagy machinery appears to be beneficial rather than harmful to certain viruses, and these therefore activate rather than inhibit autophagy-like processes (Figure 2). The small but diverse set of human tumor viruses contains examples for both autophagy-inhibitors and autophagy-inducers.

\subsection{Viral Modulation of Autophagy-Mediated Immune Defense Mechanisms}

It has been speculated that autophagy, an ancient mechanism that allows survival during nutrient deprivation, further developed during evolution to provide protection against additional forms of stress that multicellular organisms are exposed to, including infection by bacterial, protozoan and viral pathogens [121]. Research in recent years has provided conclusive evidence for autophagy playing a crucial role in host cell immunity [121]. Atg-proteins, however, may also function in immunity independently of their role in autophagy, as reported for ATG5 in macrophages infected with the protozoon Toxoplasma gondii [122].

In general, the regulation of autophagy (or of Atg-proteins) by immune signals is reciprocal and complex, and each can either induce or suppress the other [121]. Autophagy contributes to host defense in at least three ways (Figure 2). First, it targets pathogens for lysosomal degradation in a process that, more appropriately, is also referred to as xenophagy (eating of foreign matter) [123]. There is evidence that among the human tumor viruses, EBV is subject to xenophagy in epithelial cells [124].

Second, in the adaptive immune response, autophagy facilitates presentation of viral antigens on major histocompatibility complex (MHC) class II-molecules, which are usually loaded with antigen peptides derived from endocytosed pathogens [125-127]. Autophagy-mediated presentation on MHC class II has been originally described in lymphoblastoid cell lines (LCLs) for antigen peptides derived from the EBV nuclear antigen 1 (EBNA1) [125]. However, EBNA1-derived antigen processing via the 
autophagy-MHC class II-route appears to be epitope specific, and occurs only at a very low level. The latter may be due to the fact that EBNA1 localizes to the nucleus where it seems to be largely protected from autophagy [128]. Evidence for the in vivo importance of the autophagy-MHC class II pathway was provided by a study that demonstrated impaired MHC class II antigen-processing and -presentation in mice with dendritic cell specific knockout of the essential autophagy gene Atg5 [129]. A more recent study further suggests that viral antigens that are generated via an autophagy-like process can also be presented on MHC class I. However, this has only been reported during late stages of herpes simplex virus 1 (HSV-1) infection in macrophages [130].

Figure 2. Autophagy and infection by human tumor viruses.

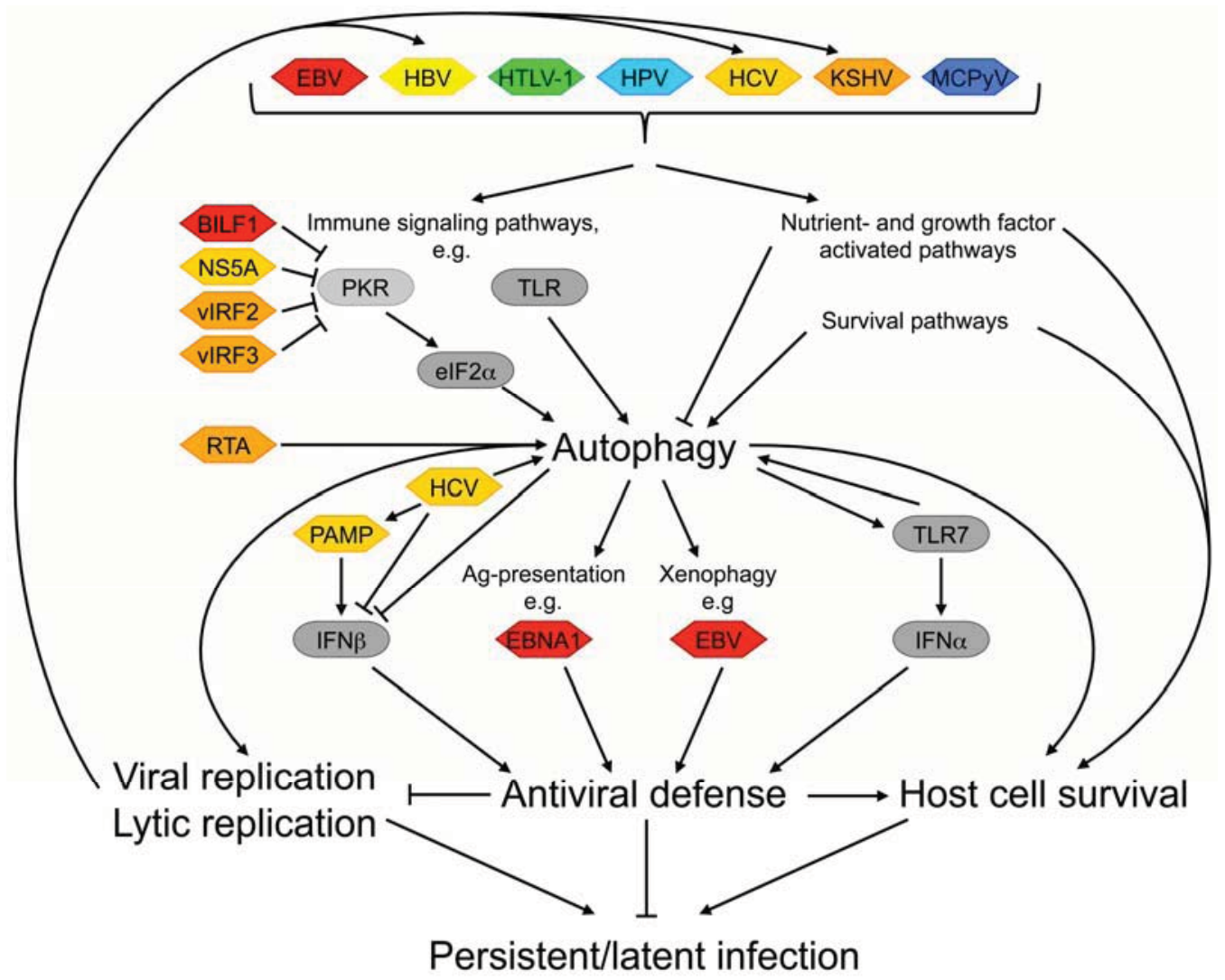

The eight established human tumor viruses interfere with a variety of host cell signaling pathways, including immune signaling pathways and pathways regulating cell growth and survival, often in response to nutrient availability (see Figures 3 and 4). See main text for details. Note: In this figure, and frequently in the literature, the term "autophagy" is used to generally denote biological processes that involve Atg-proteins, even if genuine autophagy (i.e., degradation of intracellular macromolecules/structures) was not formally examined or if the late degradation steps in the pathway appeared to be blocked (for example in several studies on $\mathrm{HBV}$ and $\mathrm{HCV}$ modulation of autophagy, see main text for details). Light grey rounded rectangles - host cell kinases; dark grey rounded rectangles - other host cell proteins; colored hexagonsviruses/viral proteins.

Lastly, autophagy affects multiple innate immune signaling pathways. For example, autophagic vesicles in plasmacytoid dendritic cells can deliver cytosolic viral replication intermediates to acidified endosomes where they activate Toll-like receptor 7 (TLR7) and induce production of interferon $\alpha$ (IFN $\alpha$ ) [131]. Conversely, TLR7 and various other TLRs, including TLRs 3 and 4 [132] as well as 
TLRs 1, 5 and 6 [133] have been reported to mediate autophagy induction in cultured macrophages when treated with the appropriate TLR-ligands. Some of the TLRs capable of signaling to the autophagy machinery also can be activated by some of the human tumor viruses including EBV, KSHV, HCV and HTLV-1 [134-137].

Another innate immunity signaling pathway triggered by viral infection comprises the double-stranded RNA sensing kinase PKR. PKR phosphorylates the $\alpha$-subunit of the eukaryotic translation initiation factor 2 (eIF2 $\alpha$ ), which inhibits translation of host cell and viral mRNAs and stimulates autophagy [138]. The precise molecular events that lead to increased autophagy downstream of eIF $2 \alpha$ are presently unknown [139]. PKR is clearly required for autophagy-induction in response to HSV-1 infection [140], yet, several other viruses also encode proteins that inhibit PKR signaling [141], including EBV BILF1 [12], KSHV viral interferon regulatory factors 2 and 3 (vIRF2/3) [98,99] and HCV non-structural protein 5A [52] (Figure 2). This supports the hypothesis that PKR plays an important role in virus-induced autophagy in general.

While the studies cited above demonstrate a positive role for autophagy in host defense, two more recent reports provided evidence that $\mathrm{HCV}$ utilizes, rather than inhibits the autophagy machinery to quench an antiviral immune response $[142,143]$. In particular, $\mathrm{HCV}$-infection and Atg-proteins were found to synergistically suppress expression of interferon $\beta$ (IFN $\beta$ or of IFN-inducible genes. These events are normally triggered upon exposure to HCV-derived pathogen associated molecular patterns [142], in cellular systems where HCV-infection increased autophagic markers [142,143] (Figure 2). It is unclear how inhibition of the IFN-regulated immune response by HCV-activated autophagy can be reconciled with the above mentioned predicted inhibition of PKR-induced autophagy by HCV NS5A [52], It is noted, that the literature on HCV and autophagy is particularly controversial in many respects. This may be due to the use of different cell lines/sublines and/or of different HCV-strains [144]. It is not clear, however, whether HCV genotypes indeed differ in their ability to induce autophagy [145] or not [55,146].

\subsection{Virally Induced Autophagy and Replication}

Some of the processes that are mediated by the autophagy machinery, such as antigen-processing or xenophagy, represent a threat to many pathogens, which, in turn, have adapted to this host response and in some cases, even found ways to take advantage of the Atg-proteins. A prominent example among the human tumor-associated viruses is provided by HCV. As discussed above, HCV may exploit the autophagy machinery to counteract an immune response [142,143]. Beyond that, multiple studies have reported that efficient HCV replication depends on Atg-proteins [55,142,146-148]. However, the various groups differ in their conclusions on the precise stage of infection during which Atg-proteins are required. Dreux et al. initially reported that replication efficiency in Huh7 cells was reduced when subgenomic HCV replicons were introduced after depletion of Atg-proteins [147]. Depletion of Atg-proteins in cells that already contained HCV subgenomic replicons, however, did not affect HCV RNA and protein levels. Thus, the authors concluded that the autophagy machinery is required for initiation of HCV replication but is dispensable once infection has been established [147]. A more recent study confirmed that Atg-proteins facilitate $\mathrm{HCV}$ replication upon initial infection [142], but there are conflicting reports on whether they are required for replication in infected 
cells $[142,146-148]$. Some studies imply that this is the case, since HCV viral particle release and survival of HCV-infected cells were decreased in the absence of Atg-proteins [142,143,145,148]. Clearly, additional studies are required to elucidate the basis for these discrepancies.

How the autophagy machinery supports HCV replication is presently unclear. For several other positive-strand RNA-viruses, such as poliovirus, dengue virus and mouse hepatitis virus, which subvert the autophagy machinery to promote their life cycles, colocalization of viral proteins or RNA with markers of autophagy-related vesicles has been observed. This is consistent with the model that the membranes of these vesicles provide a scaffold for the viral replication complex [149-153]. However, in case of HCV, currently available data varies with regard to whether and in which stage of infection there is colocalization of viral replication factors with autophagosome-like vesicular membranes [55,147,148,154].

HBV replication also appears to depend on the autophagy machinery since replication was decreased when HBV-transfected Huh7.5-cells were treated with the autophagy inhibitor 3-methyladenine (3-MA) or when VPS34 or ATG7 were depleted [27]. Studies by the same group in HBV-transgenic mice with liver specific knockout of the critical autophagy-regulator Atg5 further suggest that the autophagy machinery is required for efficient HBV DNA replication in vivo [155]. In contrast, another group found that autophagy inhibition predominantly affected viral envelopment, rather than DNA replication [36]. Whether these different results are due to different sublines of Huh7 or different HBV strains used by the two groups, as suggested by Tian et al. remains to be determined.

Both HCC-associated viruses, HBV [27,36] and HCV [55,146], have been reported to induce autophagic markers in infected cells, however, without enhancing degradation of autophagy-substrates such as long lived proteins or p62. In case of HCV the initial reports cited above have been both substantiated and debated by more recent studies that provided evidence either for the incomplete autophagic response being due to impaired maturation of HCV-induced autophagosome-like vesicles [145] at late stages or for these vesicles actually being capable of mediating autophagic degradation of their cargo [142,156]. The study by Vescovo et al. suggests a partial explanation for this discrepancies: HCV-induced autophagy seems to predominantly target lipids, whereas turnover of organelles or proteins, which is commonly examined in autophagic flux assays [101] is largely unaffected by the virus.

In KSHV infection, viral particles are produced only in the lytic phase. Overexpression of the replication and transcription activator, RTA, the master regulator of the latent-to-lytic switch increases LC3 conversion and autophagic flux in 293T- and BJAB cells [87]. Conversely, treatment with the autophagy inhibitor 3-MA or Beclin-1 depletion inhibited expression of RTA-induced lytic genes, and diminished viral genome replication in a RTA-overexpressing PEL cell line. The mechanism(s) by which RTA increases autophagy and how autophagy subsequently facilitates lytic replication remain to be determined [87]. As discussed below, KSHV encodes two other proteins, vFLIP and vBcl-2 that inhibit autophagy. Since vFLIP is expressed during both the latent and lytic phases of the viral life cycle [157], one might speculate that vFLIP inhibition of autophagy contributes to maintenance of latency. VBcl-2 expression increases early in the lytic phase [158], and hence both vFLIP and vBcl-2 may serve to limit RTA-driven autophagy and lytic replication. In summary, KSHV may have developed multiple strategies to tightly control induction of lytic replication by modulating autophagy. 


\section{Mechanisms of Viral Interference with Autophagy}

As outlined above, modulation of autophagy apparently provides certain advantages to viral invaders. Yet, only very few viruses encode proteins that directly interact with components of the autophagy machinery (Figure 2). More commonly, viruses target autophagy-regulating upstream signaling pathways, including immune signaling pathways [141].

\subsection{Viral Oncoproteins Directly Targeting the Autophagy Machinery}

\subsubsection{Beclin-1—A Popular Target with Viral Proteins}

Beclin-1 was discovered in a yeast 2-hybrid screen for interaction partners of the anti-apoptotic protein Bcl-2 [88]. Beclin-1 was the first mammalian Atg protein to be identified and the first Atg protein that was established as a tumor suppressor [118]. Binding of cellular Bcl-2 (cBcl-2) and of the viral Bcl-2 homologs encoded by KSHV (termed vBcl-2) [158,159] and murine $\gamma$-herpes virus 68, $\gamma$ HV68 (termed M11) [160] to Beclin-1 suppresses autophagy [89,161]. EBV also encodes two Bcl-2 homologs, BHRF1 [162] and BALF1 [163], but their potential interactions with Beclin-1 have not yet been examined. Upon starvation, cBcl-2 is phosphorylated by c-Jun N-terminal kinase 1 (JNK1), which causes disruption of the cBcl-2/Beclin-1 complex. In contrast, vBcl-2 lacks the relevant JNK phosphorylation sites [103] and, therefore, it constitutively associates with Beclin-1 to inhibit autophagy. It is interesting to note that several viral proteins including the EBV latent membrane protein 1 (LMP1) [13-15], KSHV ORF49 [85], HCV core and NS3, and HTLV-1 Tax [69] can activate the JNK signaling pathway, and this is predicted to activate Beclin-1 dependent autophagy. Conversely, expression of the HPV oncoprotein E7 can diminish JNK activation [67].

Another difference between $\mathrm{cBcl}-2$ and $\mathrm{vBcl}-2$ is that $\mathrm{cBcl}-2$ disrupts the Beclin-1/UVRAG complex, whereas vBcl-2 does not, and instead forms a higher order Beclin-1/UVRAG/vBcl-2 complex [161]. These results suggest that $\mathrm{cBcl}-2$ and $\mathrm{vBcl}-2$ may inhibit Beclin-1 dependent autophagy by different mechanisms: cBcl-2 may function by preventing Beclin-1 from associating with VPS34, whereas the precise molecular events by which vBcl-2 inhibits autophagy remain to be determined. Regardless, however, the fact that Beclin-1 is an established tumor suppressor suggests that its inhibition by tumor virus proteins such as vBcl-2 importantly contributes to host cell transformation [141].

As indicated above, Beclin-1 is a common target among viruses that modulate autophagy. Other viral proteins that associate with Beclin-1 include the ICP34.5 neurovirulence protein of the $\alpha$-herpesvirus HSV-1 [164], HIV-1 Nef [165] and the Influenza virus M2 protein [166]. While ICP34.5 association with Beclin-1 has been linked to inhibition of autophagy [167], it remains to be determined whether association of HIV-1 NEF or Influenza virus M2 with Beclin-1 inhibit autophagy.

\subsubsection{ATG3 Binding to FLIP-Proteins}

In addition to inhibiting autophagy through formation of a vBc12/Beclin-1 complex, KSHV also blocks this process via its FLICE-like inhibitor protein, vFLIP (encoded by ORF71/K13). vFLIP and its cellular counterpart cFLIP, inhibit death receptor-induced apoptosis [168,169] and also suppress 
starvation- or rapamycin induced formation of LC3-decorated vesicles and cell death associated with autophagy [90]. Of note, the anti-autophagic activity of vFLIP and cFLIP were independent of their anti-apoptotic activities, and both vFLIP and cFLIP were found to bind the autophagy-protein ATG3 competitively with LC3. For vFLIP, it was shown that the ability to interact with ATG3 was required for inhibition of cell death associated with autophagy [90].

\subsubsection{Interactions of Viral Proteins with Other Autophagy-Regulating Proteins}

Biochemical evidence suggests interactions of various HBV- and HCV-proteins with components of the autophagy machinery. In particular, HBV X-protein (HBx) was shown to interact with VPS34 [27] and the small surface protein SHBs with LC3 [36]. In addition, HCV non-structural protein 3 (NS3) was found to associate and to colocalize with the immunity-associated GTPase family M protein (IRGM) [47], a known regulator of autophagy in response to bacterial infections [170]. NS4B coprecipitated with exogenous Rab5 and VPS34 [48] and NS5B was shown to coprecipitate with the ATG5-protein when overexpressed in yeast, and GFP-ATG5 and NS5B colocalized in Huh-7 cells [54]. Yet, several other groups working with various Huh-7 sub-lines infected with various HCV isolates observed little or no colocalization of various HCV-proteins such as core, NS3, NS4A/B and NS5A with autophagic marker proteins $[55,145,146,148]$.

In addition to targeting autophagy regulators via protein-protein-interactions, HBV and HCV may also modulate autophagy through transcriptional activation of Beclin-1 expression. While in case of HBV, reporter assays suggested that HBx may transactivate the Beclin-1 promoter [26], mechanistic details of how HCV increased Beclin-1 expression remain to be determined [55].

\subsection{Autophagy-Regulating Signaling Pathways Targeted by Viral Oncoproteins}

Autophagy is activated above basal levels in response to diverse environmental and physiological stressors such as nutrient- or growth factor deprivation, hypoxia, ER- and redox stress, organelle damage or pathogen infection [121]. This implies that autophagy is tightly connected to cellular metabolism and to diverse stress-sensitive signaling pathways. Yet, the precise molecular links between these pathways and the autophagy machinery have not yet been fully elucidated. In addition, virtually all the major cellular stress-sensing signaling pathways have been implicated in human cancer, and most of these pathways are also modulated by tumor viruses. In this section, we describe how viruses disturb some of the central stress-sensing host cell signaling pathways and discuss potential effects on autophagy.

\subsubsection{PI3K-AKT and mTORC1 Signaling}

The PI3K-AKT signaling pathway is activated downstream of growth factor receptors such as insulin-receptor and epidermal growth factor receptor (EGFR) and regulates several key aspects of cell physiology including cell cycle, metabolism and apoptosis (Figure 3). Activation of PI3K-AKT signaling promotes cell growth, proliferation and survival [171]. A central mediator of this pathway with regard to cell growth is the (m)TOR-complex 1 (mTORC1), a multiprotein complex comprising the Ser/Thr kinase mammalian target of rapamycin (mTOR) and regulatory proteins Raptor, G $\beta \mathrm{L}$, 
PRAS40 and Deptor (reviewed in [104]). ERK signaling, decreased AMPK signaling and availability of amino acids also activate mTORC1 (see below). mTORC1 supports cell growth by activating mRNA translation and ribosome biogenesis and by inhibiting autophagy [104]. In fact, inhibition of mTORC1 and its counterparts in other organisms is sufficient to activate autophagy even in the presence of nutrients [172]. Although TOR has long been known to be a key suppressor of autophagy [172], the mechanisms by which it regulates this process in mammalian cells have much more recently been delineated and the autophagy-initiating kinase ULK1 was identified as an mTORC1-substrate (for review, see [116] (Figure 3). While mTOR is rarely mutated in human cancers [173], alterations in PI3K-AKT signaling are among the most frequent alterations observed in a wide variety of tumors [174]. Such cancers are expected to have dysregulated mTORC1 signaling and dysregulated autophagy. Autophagy dysregulation by this pathway may be common in virus-associated malignancies, too. Even though the mTOR kinase itself does not seem to be a direct target of any viral protein, all the known human tumor viruses appear to interfere with PI3K-AKT-mTOR signaling, most likely to exploit the growth- and survival promoting function of these pathways. Tumors with hyperactive mTORC1 may be sensitive to treatment with $\mathrm{mTOR}(\mathrm{C} 1)$-inhibitors such as rapamycin, and indeed, such drugs have been suggested for treating infections and/or tumors caused by EBV [175], KSHV [176,177], HBV [178], HCV [179], HPV [180] and HTLV-1 [181,182].

EBV LMP1 mimics a ligand-independent, constitutively active CD40 receptor [183] and is sufficient for transformation of rodent cells and primary B lymphocytes in vitro [184,185] and in vivo [186]. LMP1 was shown to activate the PI3K-mTOR pathway in B cell lines [21] and LMP1-expression was positively correlated with phosphorylation of mTOR and its substrates ribosomal protein S6 kinase (S6K) and eukaryotic translation initiation factor 4E-binding protein (4E-BP1) in nasopharyngeal carcinoma patient samples [20]. The second EBV encoded transmembrane protein, LMP2 [187], or more precisely, the LMP2A splice variant, is dispensable for B cell immortalization in vitro [188], but it appears to enhance LMP1's ability to promote carcinogenesis in a transgenic mouse model [189]. LMP2A was shown to activate PI3K-AKT- and mTOR signaling in several cell lines, including a nasopharyngeal carcinoma line [22-24], and in vivo, in B-cells of LMP2 transgenic mice [190]. The LMP2B splice variant lacks an N-terminal cytoplasmic domain and hence important signaling functions seen for LMP2A [191-193].

Multiple KSHV-proteins have been implicated in activation of PI3K-, AKT- and/or mTOR signaling. In particular, the viral G-protein coupled receptor homolog (vGPCR), a lytic gene, signals to mTORC1 via PI3K $\gamma$ [97], a PI3K isoform that is mainly expressed in white blood and endothelial cells and that is uniquely activated by GPCRs [97,194]. vGPCR signaling to mTORC1 drives endothelial cell proliferation [195] and mTORC1 signaling may in turn promote expression of the latent-to-lytic switch master regulator RTA [176]. The latter results may require further confirmation since the study is limited to pharmacologic inhibition of mTORC1 with rapamycin in one particular PEL cell line where rapamycin did not induce growth arrest. Moreover, the finding that mTORC1 is a positive regulator of RTA-driven lytic activation cannot be easily reconciled with another report discussed above, that provided evidence for autophagy promoting KSHV lytic replication, since autophagy is inhibited by mTORC1 [87]. Thus, additional studies are required to elucidate the regulatory connections between mTORC1, RTA and autophagy. In addition, KSHV activates PI3K-, AKT- and mTOR signaling in 
both B lymphocytes [78] and endothelial cells $[79,80]$ via its K1 protein, a constitutively active B-cell receptor homolog which is predominantly expressed during lytic replication [196-198].

Figure 3. Autophagy regulation via nutrient- and growth factor sensitive signaling pathways and points of interference by viral proteins.

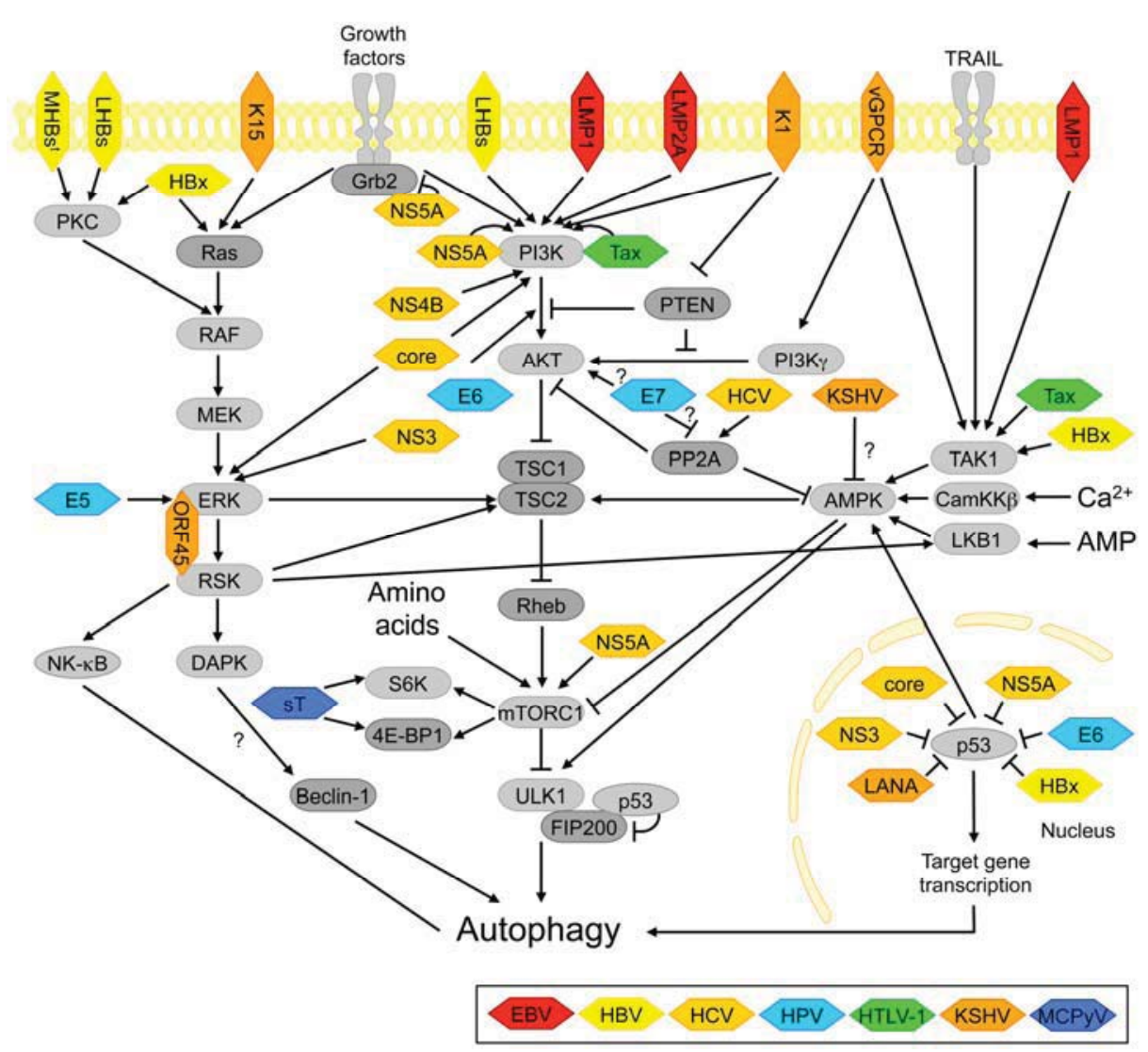

This figure gives a simplified overview of the cell's nutrient and growth-factor regulated cellular signaling pathways: (1) the PI3K pathway and its important signaling mediators AKT, the TSC1/2 GTPase activating complex for the GTPase Rheb, which activates mTORC1, and mTORC1 (note: individual complex proteins have been omitted for clarity); (2) the RAF-MEK-ERK MAPK-module and (3) the AMPK pathway. Interactions of these pathways with the p53 tumor suppressor, which is commonly inactivated by viral oncoproteins are also shown. These pathways are directly connected to the autophagy machinery via the ULK1-kinase complex and Beclin-1. See main text for additional details. See Figure 4 for AKT- and TAK1 regulation of NF-KB signaling, regulation of Beclin-1 by JNK signaling and viral modulators of the JNK pathway, as well as additional upstream regulators, downstream mediators and viral modulators of TAK1 signaling. Mechanistic details on how viral proteins interfere with nutrient- and growth factor-regulated signaling pathways are discussed in the text, except for the following: HBV LHBs and MHBs ${ }^{t}$ signal to RAF via protein kinase C (PKC) [31]. HBx can also activate PKC [199]. HCV NS5A does not directly target mTOR but its regulator FKBP38 [200] and may inhibit ERK signaling by interacting with GRB2 [50,51]. Question marks indicate that it is currently unclear whether DAPK-phosphorylation of Beclin-1 occurs physiologically, which HCV-protein is involved in inhibition of PP2A, which KSHV protein is involved in inhibition of AMPK, and whether HPV E7 activates AKT via an retinoblastoma protein dependent or independent mechanism involving PP2A [62,63]. Light grey rounded rectangles-host cell kinases; light grey ovals - host cell transcription factors; dark grey rounded rectangles-other host cell proteins; colored hexagons-viral proteins; $\rightarrow$ : activation; to $\perp$ : inhibition. -: no general consensus in the literature on activation/inhibition, outcome may be cell type specific. 
Modulation of PI3K-AKT-mTOR signaling may also play an important role in HBV-associated liver carcinogenesis. Studies in cultured cells and in clinical samples collectively suggest a model whereby PI3K-AKT-mTOR signaling is initially activated by the HBV large surface protein LHBs, whereas at later stages, PI3K-AKT-mTOR signaling suppresses LHBs-expression and HBV-replication [32-34,201].

The situation is similar in HCV infection, in that mTOR signaling suppresses viral replication, even though the virus can increase mTOR activity [202-204]. The NS5A protein may play an important role in this, since it has been reported to activate mTORC1 signaling via both PI3K-AKT-dependent [49,50,205] and independent mechanisms [200]. On the other hand, NS5A was also found to be phosphorylated in a rapamycin-sensitive manner when ectopically expressed in COS-1 cells, suggesting that it functions downstream of mTORC1 [206]. Other HCV proteins activating AKT signaling include NS4B and core [46]. It is interesting to note that the group that reported that NS4B is sufficient to induce autophagic markers did not observe alterations in mTORC1-activity by NS4B [48].

In cells expressing the HPV oncoprotein E6, mTORC1-activity is sustained even under conditions of growth factor deprivation $[58,59]$. Although controversial reports exist in the literature regarding the underlying mechanism [59,207], studies conducted in a physiologically relevant cellular system, human foreskin keratinocytes (HFKs), suggest that this is due to E6 sustaining the activity of AKT, which stimulates mTORC1 [59]. Whether this restrains autophagy-induction under these conditions remains to be investigated. The second HPV oncoprotein, E7 also has been reported to activate AKT signaling in several cell types including HFKs $[62,63]$. Although this is predicted to inhibit autophagy, E7 was found to induce an autophagy-like process in normal human keratinocytes even when the cells were grown in normal medium [68]. Additional studies are required to define the mechanism by which HPV E7 expression activates the autophagy machinery, although it has been speculated that it may arise as a consequence of metabolic stress [208], potentially due to induction of the Warburg effect by the HPV E7 protein [209] and the concomitant decrease in ATP production. Moreover, it will be interesting to investigate if autophagy is deregulated in cervical cancer cells, which co-express the E6 and E7 oncoproteins that may have opposing effects on autophagy-like processes.

Similar to HPV E6, the HTLV-1 oncoprotein Tax allows for sustained AKT phosphorylation under low serum conditions, and this may be due to Tax interacting with the regulatory p85 subunit of PI3K [70]. Another study showed that Tax-conferred growth factor independence through mTORC1 [71].

Currently, there are no reports in the literature that specifically address interference with autophagy by the most recently discovered tumor virus, MCPyV. Yet, the MCPyV small T-antigen, which is regularly expressed in MCPyV-positive tumors [75] was shown to increase phosphorylation of the two mTORC1 effectors and substrates, 4E-BP1 and S6K, potentially by inhibiting their dephosphorylation [75]. It is interesting to note that in another recent study, activating mutations in PI3K were detected almost exclusively in MCPyV negative Merkel cell carcinoma specimens [210]. This underscores the importance of PI3K signaling and its downstream targets such as mTORC1 for MCC development and supports the model that MCPyV has evolved strategies to activate this critical pathway. 


\subsubsection{ERK Signaling}

The ERK pathway represents the prototypical example of a mitogen-activated protein kinase (MAPK) cascade where ERK (a MAPK) is activated by MEK, a MAPK kinase (MAPKK), which in turn is activated by RAF, a MAPKK kinase (MAPKKK). RAF is typically activated by the small GTPase Ras downstream of receptor tyrosine protein kinases [211] (Figure 3). Many effects of ERK signaling are cell type and context dependent [212], and this may include its role in autophagy regulation. ERK signaling contributes to mTORC1 activation, which suppresses autophagy [104]. In addition, at least in certain cell types, the ERK-substrate $90 \mathrm{kD}$ ribosomal protein S6 kinase (RSK) can inhibit death-associated protein kinase (DAPK), a potential positive regulator of Beclin-1 dependent autophagy [213,214], and both ERK and RSK can inhibit the Ser/Thr-kinase LKB1 [215] and thus interfere with activation of the pro-autophagic kinase AMPK (see below) [216]. Finally, ERK may modulate autophagy via RSK-dependent activation of NF- $\mathrm{BB}$ signaling [217], which is discussed in more detail below.

Tumor viruses that interfere with ERK signaling include KSHV, HBV, HCV and HPV. KSHV modulation of ERK signaling has been studied in the context of lytic gene regulation. KSHV ORF45, an immediate early gene expressed during primary infection as well as reactivation [218] was shown to promote lytic gene expression by recruiting ERK and its substrate RSK into a common complex and by sustaining the enzymatic activity of both kinases [219]. In addition, several splice variants of the transmembrane protein K15 were also reported to activate the ERK pathway [81]. HBV activates the Ras-RAF-MEK-ERK pathway via $\mathrm{HBx}$ and the large and middle surface antigens [30-32,51,61,220-222] and HPV via its E6 and E7 oncoproteins [61]. For HCV, evidence has been provided that core and NS3 activate ERK signaling [37,38] while NS5A may suppress this pathway [50,51]. For any of the viruses discussed here, KSHV, HBV, HCV, and HPV, it remains to be examined whether their interference with ERK signaling affects autophagy.

\subsubsection{AMPK-Signaling}

The AMP-activated protein kinase, AMPK, is a major cellular energy sensor and may positively regulate autophagy by inhibiting mTORC1 (for reviews, see [104,216]). However, several studies demonstrated that AMPK can also directly target the autophagy machinery. AMPK associates with and phosphorylates the autophagy-initiating kinase ULK1 [223-226] (Figure 3). AMPK-dependent phosphorylation of ULK1 may be important for autophagosome biogenesis since it is required for correct intracellular localization of mAtg9, a putative membrane carrier protein [227,228]. AMPK activity is modulated by the cellular ATP/AMP ratio and requires phosphorylation by an upstream kinase, such as LKB1, CamKK $\beta$ or potentially TAK1, which also plays an important role in NF- $\mathrm{BB}$ activation [229]. All three of these kinases have been reported to mediate autophagy via AMPK, at least in specific cell lines and contexts [230-232]. Moreover, AMPK-dependent autophagy induction seems to require p53, which, as discussed below, is commonly inactivated by tumor viruses [233].

Reports explicitly connecting AMPK or one of its upstream kinases to human tumor viruses and autophagy are scarce in the literature. Expression of simian vacuolating virus 40 (SV40) small T antigen has been demonstrated to inhibit cell death in glucose deprived cultured cells by activating 
AMPK and increasing autophagy [234]. However, whether small T antigens of other polyomaviruses, such as that of the carcinogenic MCPyV can also activate AMPK remains to be determined. A recent study detected no evidence for AMPK activation in EBV-positive B cells that underwent autophagy in response to NF- $\mathrm{KB}$ inhibition [16], yet it cannot be ruled out that AMPK may still be important in this setting, since even basal activity of AMPK is sufficient for induction of autophagy [235,236].

However, beyond the specific context of autophagy, there is increasing evidence for crosstalk between AMPK signaling and viral infection, including infection by tumor viruses [237]. In particular, AMPK-inhibition was observed in KSHV-infected endothelial cells [79]. Moreover, in Huh-7 cells, HCV infection or the presence of a subgenomic replicon decreased AMPK-activity [238]. Conversely, pharmacologic AMPK activation blocked viral replication [238]. Since AMPK is an inhibitor of lipid biosynthesis, AMPK activation may block formation of a membranous web that is critically important for HCV replication [216,239,240]. However, since HCV induces, rather than inhibits, formation of autophagic vesicles $[48,55,142,146,147,156]$, it remains to be determined whether and under which conditions HCV-modulation of AMPK affects autophagy in infected cells.

Given that AMPK- and AKT-mTOR signaling have opposing effects on cell physiology, some findings on the biochemical and biological activities of these pathways in the context of $\mathrm{HCV}$-infection cannot be easily reconciled. AMPK activation, for instance, which decreases HCV-replication, should result in mTOR-inhibition. Yet, as was pointed out above, mTOR is also a negative regulator of $\mathrm{HCV}$-replication, and its inhibition should favor HCV replication. This suggests that AMPK and mTOR inhibit HCV-replication through different molecular mechanisms and that maximum replication should occur when both AMPK- and mTOR signaling are suppressed. Interestingly, a study that investigated biopsies of chronically hepatitis $\mathrm{C}$ infected liver tissues showed increased expression of protein phosphatase 2A (PP2A), which negatively regulates both the AMPKand the AKT-mTOR pathway in cultured cells expressing HCV proteins [241]. Clearly, additional studies are required to further characterize the profound $\mathrm{HCV}$-induced changes in the host cell signaling pathways regulating cell growth, metabolism and autophagy that are suggested by the currently available data.

Several viral oncoproteins such as EBV LMP1 [15], KSHV vGPCR [242], HBx [243] and HTLV-1 Tax [69] were shown to signal through the potential AMPK-activating kinase TAK1. TAK1-AMPK connections in the context of these viral proteins, however, have not been examined.

\subsubsection{Other Kinases Involved in Starvation-Induced Autophagy}

Kinases other than AMPK and mTOR have also been implicated in starvation-induced autophagy. Positive regulators include the IKK kinase complex (discussed in greater detail below), which was found to be important for efficient upregulation of autophagy in response to starvation [244] and JNK1 (see above), which upon starvation releases Beclin-1 from an inhibitory complex with Bcl-2 [103]. The p38 $\alpha$ kinase is a negative regulator of both basal and starvation induced autophagy and modulates trafficking of the putative membrane carrier protein mAtg9 [102]. Viral oncoproteins upregulating p38 signaling include EBV LMP1 [17,21], KSHV vGPCR [86], K15 [81] and ORF49 [85], the HBV protein HBx [29], HCV core and NS3 [37,38], the HPV E5 protein [56] and HTLV-1 Tax [69]. Conversely, HCV NS5A inhibited p38-activity [53]. JNK and p38 may also modulate autophagy 
through activating NF- $\mathrm{B}$ (see below). Lastly there is evidence from studies in yeast which require further confirmation in mammalian cells that PKR, a kinase targeted by many viruses because of its function in antiviral immune signaling (see above) may also play a role in starvation-induced autophagy [140].

\subsubsection{The p53 Tumor Suppressor}

The p53 tumor suppressor also has an important role in controlling metabolic stress [245]. In response to various autophagy-inducing stimuli, including nutrient-deprivation and mTOR-inhibition, nuclear p53 induces transcription of genes that positively regulate autophagy such as the lysosomal protein Damage-Regulated Autophagy Modulator (DRAM) [246] and Sestrin 2 [247,248]. Moreover, p53 transcriptionally activates negative regulators of the PI3K-AKT-mTOR signaling pathway such as AMPK $\beta$, TSC2, PTEN and IGF-BP3, at least in certain cell types and in response to particular stressors [249]. A notable exception to the general trend that p53-target genes promote autophagy is the TP53-Induced Glycolysis and Apoptosis Regulator (TIGAR), a fructose-2,6-bisphosphatase [250] that inhibits autophagy by decreasing ROS-levels under conditions of nutrient starvation or metabolic stress [251]. In contrast to nuclear p53, cytoplasmic p53 mutants inhibit autophagy by interacting with FIP200, a component of the autophagy-initiating ULK1-kinase complex [252,253].

Various viral oncoproteins have been reported to interfere with p53 function but whether this contributes to autophagy modulation by any of the human tumor viruses has not been examined yet. The most prominent examples include SV40 large T antigen, Adenovirus E1b and HPV E6, which all form complexes with p53 and functionally inactivate it (reviewed in [254]). In particular, HPV E6 recruits the host cell encoded E3 ubiquitin ligase UBE3A (E6AP) to target p53 for ubiquitination and proteasomal degradation $[60,255,256]$. The immediate benefit of E6-mediated p53-inactivation for the virus presumably consists in abrogation of the p53-dependent apoptotic response which otherwise would be triggered to counteract excessive cell proliferation driven by E7 [5]. In addition, KSHV latency associated nuclear antigen (LANA) has been reported to interact with p53 and inhibit its transcriptional activity [82]. The HBx protein was reported to interact with p53 in HBV-positive HCC tissue lysates [28], and there have also been reports for interactions of the HCV proteins core $[42,43,45]$, NS3 [41] and NS5A with p53 [44]. HTLV-1 Tax also inhibits p53 transcriptional activity [73, 257-259]. Even though p53 was originally discovered through its interaction with SV40 large $\mathrm{T}$ antigen [257] there is no evidence that MCPyV large T antigen associates with p53.

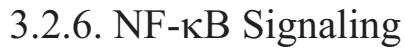

Nuclear factor $\kappa \mathrm{B}$ transcription factors are executing the biological activities of multiple stress-sensitive signaling pathways, including immune signaling pathways (Figure 4). Not surprisingly, they regulate expression of a broad variety of genes related to immunity, cell proliferation, differentiation and survival $[139,229]$. An overview of the NF- $\kappa B$ signaling network as it pertains to autophagy is given in Figure 4.

There is complex and reciprocal regulation of $\mathrm{NF}-\kappa \mathrm{B}$ signaling and autophagy and both activation and suppression of one by the other have been observed. Many of the reported effects, however, may be specific to the cell type and/or the autophagy-modulating treatment applied. For example, in 
HTLV-1 transformed cells and ATL cell lines, autophagy induced by Geldanamycin treatment inhibited NF- $\mathrm{KB}$ signaling by selectively degrading IKK and NIK [260,261]. On the other hand, in mouse embryonic fibroblasts (MEFs), Atg-proteins ATG5, ATG7, Beclin-1 and VPS34 were required for activation of NF- $\kappa$ B by tumor necrosis factor- $\alpha$ (TNF $\alpha)$ [262]. Conversely, the NF- $\kappa B$ family member p65 positively regulated basal autophagy by transactivating the Beclin-1 promoter in T-cells [263]. However, NF- $\kappa$ B suppressed TNF $\alpha$-, but not starvation-induced autophagy in Ewing sarcoma-cells [264]. Finally, a recent study suggested that NF- $\kappa B$ signaling can be activated in parallel with autophagy by pro-autophagic stimuli via a mechanism that involves the TAK1-binding proteins 2 and 3 (TAB2/3) switching from binding and inhibiting Beclin-1 under basal conditions to associating and activating TAK1 [265]. Moreover, the NF-кB-regulating kinase IKK $\beta$ can promote autophagy independently of the transcription factor NF- $\mathrm{BB}$. AMPK and JNK appeared to be important downstream mediators of IKK in this context [244]. Conversely, in B cell lymphomas, IKK inhibited autophagy as

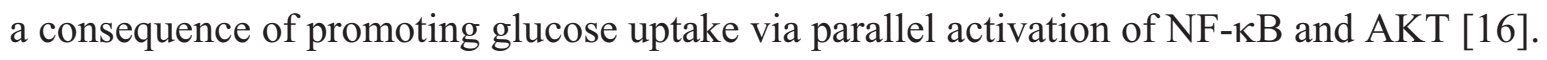

Figure 4. Autophagy regulation via the NF- $\kappa B$ pathway, and points of interference by viral proteins.

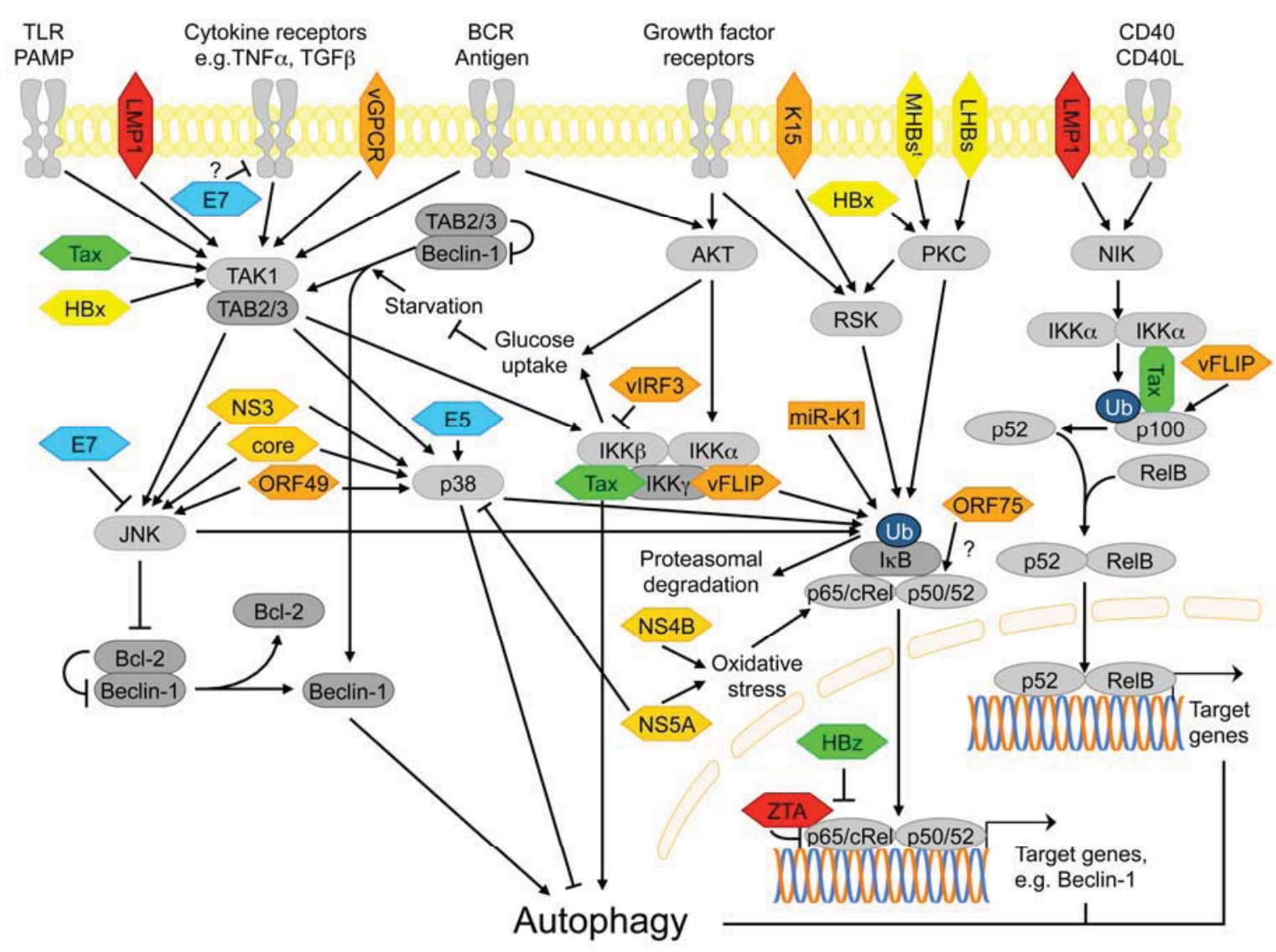

\section{HBV HCV HPV HTLV-1 KSHV MCPyV}

This figure gives a simplified overview of the cellular signaling pathways that regulate NF- $\mathrm{B}$ transcription factors. These transcription factors function as homo- or heterodimers formed by the five proteins of the

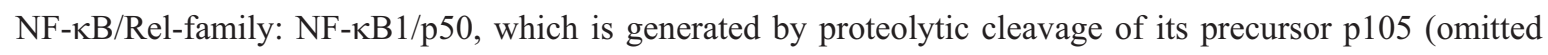
for clarity), NF-кB2/p52 generated by cleavage of the precursor p100, RelA/p65, RelB and c-Rel. The 
canonical NF-kB pathway is triggered by B-cell-, T-cell, cytokine-, growth factor- or Toll-like receptor signaling, which lead to activation of the inhibitor of $\kappa B$ kinase (IKK) complex in the cytoplasm. This complex consists of the catalytic subunits IKK $\alpha$ and IKK $\beta$ and the negative regulatory subunit IKK $\gamma / \mathrm{NEMO}$ (NF- $\mathrm{kB}$ essential modulator). IKK activation often also requires the transforming growth factor $\beta$-activated protein kinase 1 (TAK1). IKK complexes phosphorylate an inhibitor of $\kappa B$ (I $\kappa B$ ) protein, which binds NF- $\mathrm{kB}$ dimers and retains them in the cytoplasm. Phosphorylation by IKK $\beta$ induces ubiquitination and

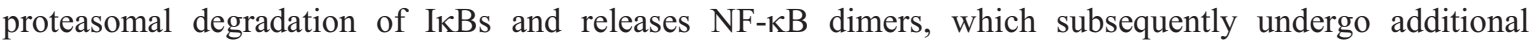
phosphorylation and acetylation events (omitted for clarity) and translocate to the nucleus to activate transcription of their target genes. Non-canonical NF- $\mathrm{BB}$ activation involves NF- $\mathrm{BB}$-inducible kinase (NIK) mediated activation of IKK $\alpha$ homodimers, which then phosphorylate the NF- $\mathrm{KB} 2 / \mathrm{p} 100$ precursor. This allows proteolytic processing of $\mathrm{p} 100$ to $\mathrm{p} 52$ which associates with RelB to form a functional transcription factor complex that enters the nucleus [229]. See main text for additional details and Figure 3 for additional autophagy-regulating pathways downstream of AKT and TAK1 and for upstream regulation of RSK. Specific tumor virus derived surface antigens/pathogen associate molecular patterns (PAMPs) activating the immune receptors shown in this figure have been omitted for clarity. Mechanistic details on how viral proteins interfere with NF- $\mathrm{kB}$ signaling have been included and are discussed in the text, except for the following: HTLV-1 Tax and KSHV vFLIP interact with IKK $\gamma$ [266-270] and stimulate p100 expression and processing independently of NIK, whereas Tax may also directly interact with IKK $\alpha$ and p100 [271-273]. Question marks indicate that it is not clear at the moment where HPV E7 interferes with TNF $\alpha$ - and TGF $\beta$-receptor signaling, and by which mechanism KSHV ORF75 activates NF-KB-dependent transcription. Light grey rounded rectangles - host cell kinases; light grey ovals—-host cell transcription factors; dark grey rounded rectangles - other host cell proteins; colored hexagons-viral proteins; colored box-viral microRNA; $\rightarrow$ : activation; to $\perp$ : inhibition. -: no general consensus in the literature on activation/inhibition; outcome may be cell type specific.

The NF- $\kappa \mathrm{B}$ pathway is a common target of several of the human tumor viruses. NF- $\kappa \mathrm{B}$ signaling plays a central role throughout the entire life cycle of the $\gamma$-herpesviruses EBV and KSHV and is constitutively activated during latency [274]. This is largely due to the action of LMP1 and vFLIP, in

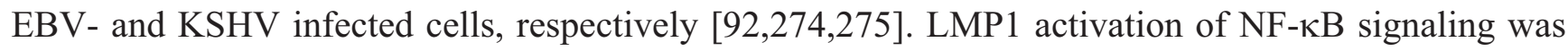
shown to suppress autophagy in B cells, a natural host of EBV [16], while vFLIP was shown to inhibit autophagy by targeting ATG3 [90] (see above). So far, no studies have implicated activation of NF- $\mathrm{B}$ signaling in autophagy regulation by vFLIP. EBV and KSHV each express additional regulators of NF- $\kappa$ B signaling [274]. The EBV immediate early protein ZTA, which is involved in the latent-to-lytic switch, inhibits the transcriptional activity of p65 [25], while KSHV microRNA miR-K1 and the vGPCR enhance NF- $\kappa B$ activity [91,93-95]. In addition, ORF75 and K15 may activate NF- $\kappa B$ signaling and vIRF3 acts as a suppressor [93,100]. The effect of KSHV K1 on NF- $\mathrm{KB}$ activity is controversial in the literature [93,100]

There is evidence that HBV HBx and a truncated form of the middle surface antigen (MHBs ${ }^{\mathrm{t}}$ can activate NF- $\kappa \mathrm{B}$-dependent transcription, and this may contribute to enhanced tumor burden in $\mathrm{MHBs}^{\mathrm{t}}$ transgenic mice $[31,35]$. In the context of HCV infection, NF- $\kappa B$, along with p38, JNK and ERK1/2 is activated as a consequence of ROS production in tissue culture cells [276]. This causes increased production of TGF $\beta 1$ [276], a cytokine that promotes autophagy in HCC cell lines [277]. Evidence has been provided for NS4B [40] and NS5A [39], respectively, being important for the induction of oxidative stress by $\mathrm{HCV}$. Additional $\mathrm{HCV}$ proteins shown to activate NF- $\kappa \mathrm{B}$, potentially via the 
JNK- and p38 pathways include core and NS3 [37]. There is no evidence that HBV and HCV modulate autophagy through these pathways.

HPV positive cervical cancer cells are resistant to cytostatic effects of TNF $\alpha$ [64] and TGF $\beta$ [65], which both act via NF- $\mathrm{B}$ and can activate autophagy. The E7 oncoprotein was shown to mediate the resistance to TNF $\alpha$ and TGF $\beta$-induced growth inhibition [64,65], and to suppress TNF $\alpha$-induced NF- $\kappa \mathrm{B}$-activation when expressed in cervical epithelial cells [66]. Whether these effects of E7 are associated with altered host cell autophagy has not been determined.

In HTLV-1 infected cells, NF- $\kappa \mathrm{B}$ is constitutively activated, predominantly via the non-canonical pathway. Even though the Tax oncoprotein upregulates both canonical and non-canonical NF- $\kappa \mathrm{B}$ signaling [74,76], the HTLV-1 encoded basic leucine zipper transcription factor HBZ selectively interferes with the canonical pathway [77]. As described in a previous paragraph, autophagy was found to inhibit NF- $\mathrm{BB}$ signaling when HTLV-1 transformed cells and ATL-cell lines were treated with Geldanamycin, and this was suggested as a potential therapeutic strategy for ATL [278].

\subsubsection{Signaling Pathways Activated by ER Stress}

The endoplasmic reticulum (ER) is the major cellular site for folding and maturation of secreted and transmembrane proteins. ER stress ensues when the number of unfolded and/or misfolded proteins that enter the ER exceeds the capacity of the ER chaperone machinery and triggers a regulatory response termed the unfolded protein response (UPR) that adjusts the ER work load to its folding/refolding capacity [279]. Moreover, the UPR also activates autophagy [139]. The signaling pathways that activate the UPR have been reviewed in detail elsewhere $[279,280]$ and are outlined in Figure 5.

Ectopic expression of the EBV oncoprotein LMP1 causes ER stress and activates all three arms of the UPR [19]. Conversely, PERK-dependent phosphorylation of elF2 $\alpha$ and activation of ATF4 increased LMP1 expression [19]. It is interesting to note that LMP1, when overexpressed at low levels, activates NF- $\mathrm{KB}$ signaling rather than the UPR [19,281]. Importantly, however, vast variations in LMP1 levels spanning up to two orders of magnitude have been observed in EBV-infected clonal lymphoblast populations [282]. Moreover, induction of NF-kB- and of PERK-elF2 $\alpha$ signaling by LMP1 are independent and require different domains of LMP1 [19,282]. Interestingly, LMP1 also induces autophagy in a dose-dependent manner via the same domains that are also involved in UPR-activation, and autophagy mediates LMP1 degradation [18]. Thus, it is tempting to speculate that in fact ER stress caused by high levels of LMP1 is the trigger for autophagy upregulation [283]. Therefore, this pro-autophagic function of LMP1 when expressed at high levels is not inconsistent with a more recent study that reported suppression of autophagy by LMP1 signaling through IKK $\beta / \mathrm{NF}-\kappa \mathrm{B}$ due to increased capacity for glucose uptake [16]. Whether the second oncogenic $\gamma$ herpesvirus, KSHV, also modulates ER stress and the UPR is not known at present.

Ectopic expression of the HBV small surface protein SHBs was reported to be sufficient for the induction of autophagic markers, and the underlying mechanism involved upregulation of all three arms of the UPR [36]. In addition, mutant versions of the large surface protein LHBs were reported to induce ER stress, however, a potential effect on autophagy was not explicitly examined [33]. 
Figure 5. Autophagy regulation by ER stress/UPR signaling pathways and points of interference by viral proteins.

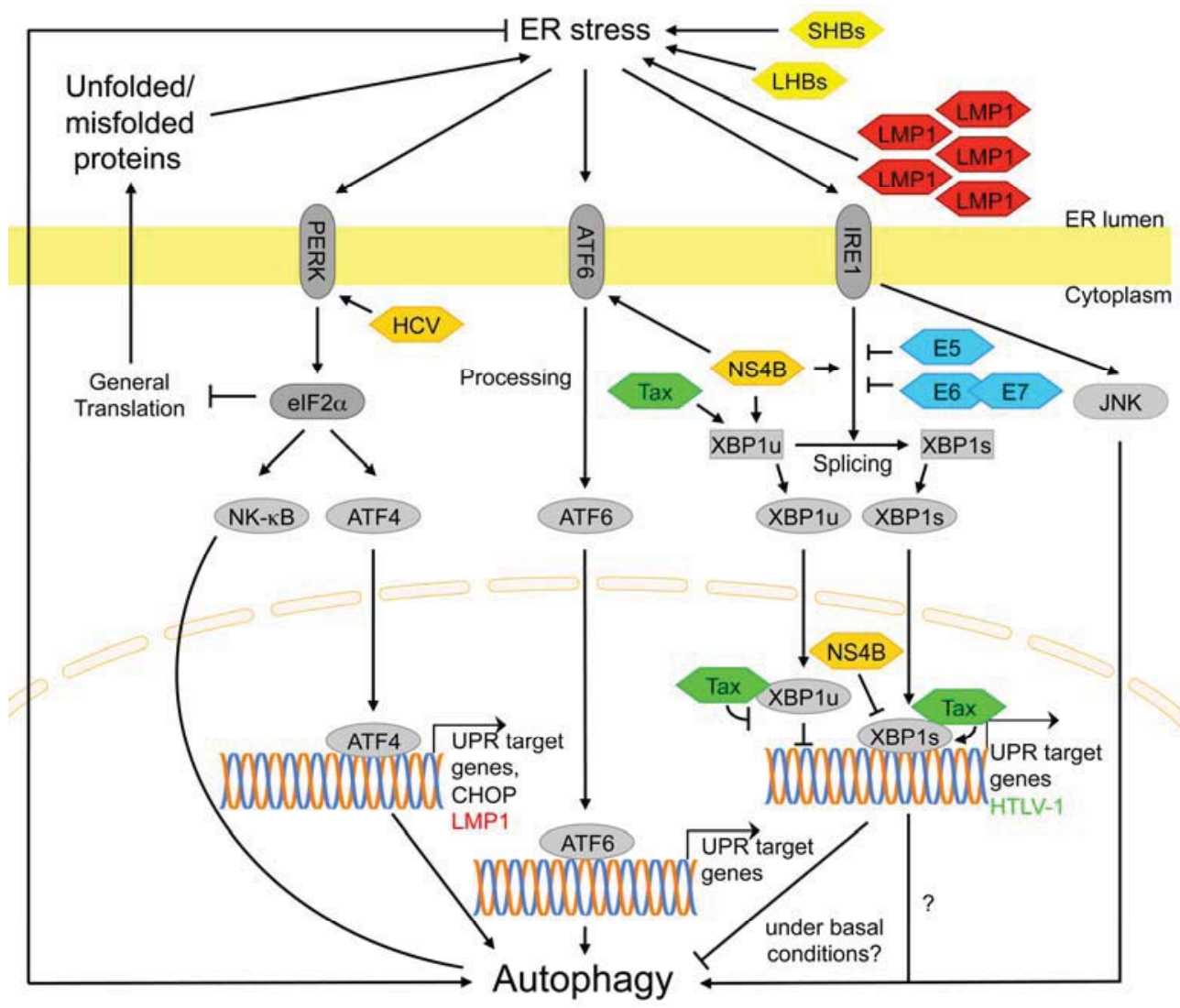

\section{EBV HBV HCV HPV HTLV-1 KSHV MCPYV}

The unfolded protein response (UPR) is triggered by endoplasmic reticulum (ER) stress and comprises three branches, each of which involves an ER transmembrane protein that senses the protein folding status in the ER and transduces this information to the cytosol. In the first branch, upon ER stress, the bifunctional inositol requiring enzyme 1 (IRE1) oligomerizes and autophosphorylates and thereby activates its endoribonuclease activity. This allows for splicing of an mRNA that encodes the transcription factor X-box binding protein 1 (XBP1). The product of the spliced XBP1-mRNA (XBP1s), in turn, upregulates expression of UPR target genes, including chaperones and ER-associated degradation (ERAD) proteins. The product of the unspliced $\mathrm{XBP} 1-\mathrm{mRNA}(\mathrm{XBP} 1 \mathrm{u})$ acts as a transcriptional repressor. In the second branch, ER stress triggers processing of activating transcription factor 6 (ATF6), which spans the ER membrane as an inactive precursor. Subsequently, the cytosolic ATF6 fragment enters the nucleus and activates expression of UPR target genes. In the third branch, ER stress activates PKR-like eIF2 $\alpha$ kinase (PERK), which phosphorylates eIF2 $\alpha$ and shuts down mRNA translation to reduce the number of proteins entering the ER. In parallel, PERK selectively promotes translation of certain stress-associated factors such as the ATF4 transcription factor. IRE1-, ATF6- and PERK signaling are activated independently but mutually reinforce each other, resulting in partially overlapping sets of UPR target genes. These UPR target genes include components of the autophagy machinery, and activation of autophagy allows degradation of ER domains that contain misfolded and aggregated proteins $[284,285]$. Note that eIF2 $\alpha$ phosphorylation at the PERK-target site, S51, is also required for autophagy in response to other stressors, including viral infection, when eIF2 $\alpha$ Ser51 is phosphorylated by PKR [140]. The molecular events that cause induction of autophagy downstream of eIF2 $\alpha$ phosphorylation are incompletely understood, with the exception of the above mentioned transcriptional effects on autophagy genes [139]. Additional mechanisms of autophagy induction by ER stress may include 
IRE1 signaling to JNK [286], a known kinase of Beclin-1, and PERK-mediated NF-אB activation [287,288]. See Figure 4 for additional host cell signaling pathways and viral proteins modulating NF- $\mathrm{kB}$ and JNK signaling, and events downstream of JNK-activation that contribute to autophagy-modulation. Mechanistic details on how viral proteins interfere with UPR signaling are discussed in the text. The question marks indicate that the finding of XBP1 increasing autophagy under basal conditions so far is limited to neurons [289]. This implies that XBP1 suppresses autophagy and gives rise to the hypothesis that the XBP1 branch of the UPR functions to prevent excessive autophagy upon ER stress. Additional studies are required to test this possibility $[289,290]$ and to clarify whether and under which conditions XBP1 activates or inhibits autophagy. Light grey rounded rectangles - host cell kinases; light grey ovals - host cell transcription factors; light grey boxes-host cell mRNAs; dark grey rounded rectangles-other host cell proteins; colored hexagons-viral proteins; $\rightarrow$ : activation; to $\perp$ : inhibition. -: no general consensus in the literature on activation/inhibition; outcome may be cell type specific.

Multiple in vitro [48,142,146,291,292] and in vivo [293,294] studies collectively suggest that $\mathrm{HCV}$-infection activates upstream regulators in all three branches of the UPR, but this does not lead to the induction of UPR-responsive genes [291-294]. Mechanistically, at least in the XBP1-branch of the UPR, the NS4B protein may be responsible for increasing XBP1-mRNA levels and splicing, but also for suppressing the transcriptional activator function of spliced XBP1 [291,292]. However, two studies provide evidence that the activators of the three UPR signaling pathways, PERK, ATF6 and IRE1, as well as a PERK-target gene, the transcription factor $\mathrm{C} / \mathrm{EBP}$-homologous protein $(\mathrm{CHOP})$, play an important role upstream of the $\mathrm{HCV}$-induced autophagy-like process in promoting viral replication $[142,146]$ and in suppressing the antiviral immune response [142]. Thus, additional studies are required to elucidate how HCV perturbs UPR signaling and autophagy in infected cells.

Little is known regarding modulation of ER-stress pathways by high-risk HPV proteins. There is evidence that in human keratinocytes, E5, and also E6/E7 suppress activation of the ER stress factor XBP1 under basal conditions, i.e., in the absence of ER- or other forms of stress [57]. Of note, XBP1 appears to suppress autophagy under these conditions, at least in neurons, giving rise to the hypothesis that suppression of XBP1 signaling by HPV-proteins increases basal autophagy [289,290]. Although basal autophagy levels may indeed be elevated in HPV positive cells [68], additional studies are required to clarify the relationship between HPV proteins, ER stress signaling pathways and autophagy.

Conversely, there is evidence that HTLV-1 via its Tax-protein upregulates XBP1 transcription (but not splicing) in unstressed cells, and vice versa. The mechanism may involve physical interaction between Tax and the protein products of both the unspliced and the spliced XBP1-mRNAs [72]. While Tax expression increased UPR signaling under basal conditions, ER stress did not increase HTLV1-expression despite increasing XBP1-transcription and splicing. It remains to be determined whether the Tax-XBP1-interaction affects basal- or stress-induced autophagy in HTLV1-infected cells.

\section{Concluding Remarks}

By mediating turnover and recycling of macromolecular and supramolecular intracellular structures, autophagy plays a central role in maintaining cellular homeostasis under physiologic conditions as well as under conditions of stress. Accordingly, this process is regulated by virtually all cellular signaling pathways that sense cell-intrinsic or environmental perturbations. These networks include immune signaling pathways and indeed, autophagy is emerging as an important defense mechanism 
against pathogens, including viruses. A small subset of viruses is known to cause or at least contribute to a variety of human cancers and a large number of studies support the notion that infection with these viruses disturbs signaling networks far beyond pathways primarily associated with immunity. Indeed, signaling pathways that primarily control cell growth, proliferation and survival, i.e., processes that are generally deregulated in cancer cells, are affected as well. These pathways are also connected to regulation of autophagy. With exception of the most recently discovered tumor virus, MCPyV, there is evidence that all of the established human tumor viruses induce hallmarks of autophagy in their host cells. Whether this represents genuine induction of autophagy has not been formally demonstrated in all cases. Only very few tumor virus proteins have been demonstrated to interact directly with autophagy-regulating proteins, and many studies reporting interference with upstream signaling pathways capable of modulating autophagy did not explicitly examine potential effects on autophagy. At least for some of the human tumor viruses, additional studies are necessary to further substantiate their connection to autophagy or to autophagy-like processes, to further elucidate the underlying molecular mechanisms and to provide answers to the key questions of how host cell autophagy affects the viral life cycle and how modulation of the autophagy machinery contributes to the development of virus-induced cancers. The current literature does not provide a uniform picture of whether viruses in general are threatened by or benefit from a functional host cell autophagy machinery and whether they have evolved to inhibit autophagy (or at least some steps in that process) or to exploit it to their own advantage. The answers to these questions may differ for different human tumor viruses.

\section{Acknowledgements}

Work in K.M.'s laboratory is supported by grants R01CA066980, R01CA081135, P50HG004233 and U01CA141583 from the National Institutes of Health. H.I.D.M. was the recipient of graduate fellowships from the Bavarian State Ministry of Sciences, Research and the Arts, the German Academic Exchange Service and the German National Academic Foundation. We apologize to those authors whose work could not be cited owing to space limitations.

\section{Conflict of Interest}

The authors declare no conflict of interest.

\section{References}

1. Kochel, T.; Aguilar, P.; Felices, V.; Comach, G.; Cruz, C.; Alava, A.; Vargas, J.; Olson, J.; Blair, P. Molecular epidemiology of dengue virus type 3 in Northern South America: 2000-2005. Infect. Genet. Evol. 2008, 8, 682-688.

2. Moore, P.S.; Chang, Y. Why do viruses cause cancer? Highlights of the first century of human tumour virology. Nat. Rev. Cancer 2010, 10, 878-889.

3. Shah, K.M.; Young, L.S. Epstein-Barr virus and carcinogenesis: Beyond Burkitt's lymphoma. Clin. Microbiol. Infect. 2009, 15, 982-988.

4. Tsai, W.L.; Chung, R.T. Viral hepatocarcinogenesis. Oncogene 2010, 29, 2309-2324. 
5. McLaughlin-Drubin, M.E.; Munger, K. Oncogenic activities of human papillomaviruses. Virus Res. 2009, 143, 195-208.

6. Matsuoka, M; Jeang, K.T. Human T-cell leukemia virus type 1 (HTLV-1) and leukemic transformation: Viral infectivity, Tax, HBZ and therapy. Oncogene 2011, 30, 1379-1389.

7. Mesri, E.A.; Cesarman, E.; Boshoff, C. Kaposi's sarcoma and its associated herpesvirus. Nat. Rev. Cancer 2010, 10, 707-719.

8. McLaughlin-Drubin, M.E.; Munger, K. Viruses associated with human cancer. Biochim. Biophys. Acta 2008, 1782, 127-150.

9. Dziurzynski, K.; Chang, S.M.; Heimberger, A.B.; Kalejta, R.F.; McGregor Dallas, S.R.; Smit, M.; Soroceanu, L.; Cobbs, C.S. Consensus on the role of human cytomegalovirus in glioblastoma. Neuro. Oncol. 2012, 14, 246-255.

10. Martin, D.; Gutkind, J.S. Human tumor-associated viruses and new insights into the molecular mechanisms of cancer. Oncogene 2008, 2, S31-S42.

11. Schwarz, E.; Freese, U.K.; Gissmann, L.; Mayer, W.; Roggenbuck, B.; Stremlau, A.; zur Hausen, $\mathrm{H}$. Structure and transcription of human papillomavirus sequences in cervical carcinoma cells. Nature 1985, 314, 111-114.

12. Beisser, P.S.; Verzijl, D.; Gruijthuijsen, Y.K.; Beuken, E.; Smit, M.J.; Leurs, R.; Bruggeman, C.A.; Vink, C. The Epstein-Barr virus BILF1 gene encodes a G protein-coupled receptor that inhibits phosphorylation of RNA-dependent protein kinase. J. Virol. 2005, 79, 441-449.

13. Eliopoulos, A.G.; Blake, S.M.; Floettmann, J.E.; Rowe, M.; Young, L.S. Epstein-Barr virusencoded latent membrane protein 1 activates the JNK pathway through its extreme $\mathrm{C}$ terminus via a mechanism involving TRADD and TRAF2. J. Virol. 1999, 73, 1023-1035.

14. Eliopoulos, A.G.; Young, L.S. Activation of the cJun N-terminal kinase (JNK) pathway by the Epstein-Barr virus-encoded latent membrane protein 1 (LMP1). Oncogene 1998, 16, 1731-1742.

15. Uemura, N.; Kajino, T.; Sanjo, H.; Sato, S.; Akira, S.; Matsumoto, K.; Ninomiya-Tsuji, J. TAK1 is a component of the Epstein-Barr virus LMP1 complex and is essential for activation of JNK but not of NF-kappaB. J. Biol. Chem. 2006, 281, 7863-7872.

16. Sommermann, T.G.; O'Neill, K.; Plas, D.R.; Cahir-McFarland, E. IKKbeta and NF-kappaB transcription govern lymphoma cell survival through AKT-induced plasma membrane trafficking of GLUT1. Cancer Res. 2011, 71, 7291-7300.

17. Eliopoulos, A.G.; Gallagher, N.J.; Blake, S.M.; Dawson, C.W.; Young, L.S. Activation of the p38 mitogen-activated protein kinase pathway by Epstein-Barr virus-encoded latent membrane protein 1 coregulates interleukin-6 and interleukin-8 production. J. Biol. Chem. 1999, 274, 16085-16096.

18. Lee, D.Y.; Sugden, B. The latent membrane protein 1 oncogene modifies B-cell physiology by regulating autophagy. Oncogene 2008, 27, 2833-2842.

19. Lee, D.Y.; Sugden, B. The LMP1 oncogene of EBV activates PERK and the unfolded protein response to drive its own synthesis. Blood 2008, 111, 2280-2289.

20. Chen, J.; Hu, C.F.; Hou, J.H.; Shao, Q.; Yan, L.X.; Zhu, X.F.; Zeng, Y.X.; Shao, J.Y. EpsteinBarr virus encoded latent membrane protein 1 regulates mTOR signaling pathway genes which predict poor prognosis of nasopharyngeal carcinoma. J. Transl. Med. 2010, 8, 30. 
21. Lambert, S.L.; Martinez, O.M. Latent membrane protein 1 of EBV activates phosphatidylinositol 3-kinase to induce production of IL-10. J. Immunol. 2007, 179, 8225-8234.

22. Moody, C.A.; Scott, R.S.; Amirghahari, N.; Nathan, C.O.; Young, L.S.; Dawson, C.W.; Sixbey, J.W. Modulation of the cell growth regulator mTOR by Epstein-Barr virus-encoded LMP2A. J. Virol. 2005, 79, 5499-5506.

23. Morrison, J.A.; Klingelhutz, A.J.; Raab-Traub, N. Epstein-Barr virus latent membrane protein 2A activates beta-catenin signaling in epithelial cells. J. Virol. 2003, 77, 12276-12284.

24. Scholle, F.; Bendt, K.M.; Raab-Traub, N. Epstein-Barr virus LMP2A transforms epithelial cells, inhibits cell differentiation, and activates Akt. J. Virol. 2000, 74, 10681-10689.

25. Morrison, T.E.; Kenney, S.C. BZLF1, an Epstein-Barr virus immediate-early protein, induces p65 nuclear translocation while inhibiting p65 transcriptional function. Virology 2004, 328, 219232.

26. Tang, H.; Da, L.; Mao, Y.; Li, Y.; Li, D.; Xu, Z.; Li, F.; Wang, Y.; Tiollais, P.; Li, T.; et al. Hepatitis B virus X protein sensitizes cells to starvation-induced autophagy via up-regulation of beclin 1 expression. Hepatology 2009, 49, 60-71.

27. Sir, D.; Tian, Y.; Chen, W.L.; Ann, D.K.; Yen, T.S.; Ou, J.H. The early autophagic pathway is activated by hepatitis B virus and required for viral DNA replication. Proc. Natl. Acad. Sci. U. S. A. 2010, 107, 4383-4388.

28. Feitelson, M.A.; Zhu, M.; Duan, L.X.; London, W.T. Hepatitis B x antigen and p53 are associated in vitro and in liver tissues from patients with primary hepatocellular carcinoma. Oncogene 1993, 8, 1109-1117.

29. Tarn, C.; Zou, L.; Hullinger, R.L.; Andrisani, O.M. Hepatitis B virus X protein activates the p38 mitogen-activated protein kinase pathway in dedifferentiated hepatocytes. J. Virol. 2002, 76, 9763-9772.

30. Benn, J.; Schneider, R.J. Hepatitis B virus HBx protein activates Ras-GTP complex formation and establishes a Ras, Raf, MAP kinase signaling cascade. Proc. Natl. Acad. Sci. U. S. A. 1994, 91, 10350-10354.

31. Hildt, E.; Munz, B.; Saher, G.; Reifenberg, K.; Hofschneider, P.H. The PreS2 activator MHBs(t) of hepatitis B virus activates c-raf-1/Erk2 signaling in transgenic mice. EMBO J. 2002, 21, $525-535$.

32. Liu, H.; Xu, J.; Zhou, L.; Yun, X.; Chen, L.; Wang, S.; Sun, L.; Wen, Y.; Gu, J. Hepatitis B virus large surface antigen promotes liver carcinogenesis by activating the Src/PI3K/Akt pathway. Cancer Res. 2011, 71, 7547-7557.

33. Hsieh, Y.H.; Su, I.J.; Wang, H.C.; Chang, W.W.; Lei, H.Y.; Lai, M.D.; Chang, W.T.; Huang, W. Pre-S mutant surface antigens in chronic hepatitis B virus infection induce oxidative stress and DNA damage. Carcinogenesis 2004, 25, 2023-2032.

34. Teng, C.F.; Wu, H.C.; Tsai, H.W.; Shiah, H.S.; Huang, W.; Su, I.J. Novel feedback inhibition of surface antigen synthesis by mammalian target of rapamycin (mTOR) signal and its implication for hepatitis B virus tumorigenesis and therapy. Hepatology 2011, 54, 1199-1207.

35. Meyer, M.; Caselmann, W.H.; Schluter, V.; Schreck, R.; Hofschneider, P.H.; Baeuerle, P.A. Hepatitis B virus transactivator MHBst: Activation of NF-kappa B, selective inhibition by antioxidants and integral membrane localization. EMBO J. 1992, 11, 2991-3001. 
36. Li, J.; Liu, Y.; Wang, Z.; Liu, K.; Wang, Y.; Liu, J.; Ding, H.; Yuan, Z. Subversion of cellular autophagy machinery by hepatitis B virus for viral envelopment. J. Virol. 2011, 85, 6319-6333.

37. Dolganiuc, A.; Oak, S.; Kodys, K.; Golenbock, D.T.; Finberg, R.W.; Kurt-Jones, E.; Szabo, G. Hepatitis $\mathrm{C}$ core and nonstructural 3 proteins trigger toll-like receptor 2-mediated pathways and inflammatory activation. Gastroenterology 2004, 127, 1513-1524.

38. Erhardt, A.; Hassan, M.; Heintges, T.; Haussinger, D. Hepatitis C virus core protein induces cell proliferation and activates ERK, JNK, and p38 MAP kinases together with the MAP kinase phosphatase MKP-1 in a HepG2 Tet-Off cell line. Virology 2002, 292, 272-284.

39. Gong, G.; Waris, G.; Tanveer, R.; Siddiqui, A. Human hepatitis C virus NS5A protein alters intracellular calcium levels, induces oxidative stress, and activates STAT-3 and NF-kappa B. Proc. Natl. Acad. Sci. U. S. A. 2001, 98, 9599-9604.

40. Li, S.; Ye, L.; Yu, X.; Xu, B.; Li, K.; Zhu, X.; Liu, H.; Wu, X.; Kong, L. Hepatitis C virus NS4B induces unfolded protein response and endoplasmic reticulum overload response-dependent NF-kappaB activation. Virology 2009, 391, 257-264.

41. Ishido, S.; Hotta, H. Complex formation of the nonstructural protein 3 of hepatitis $\mathrm{C}$ virus with the p53 tumor suppressor. FEBS Lett. 1998, 438, 258-262.

42. Kao, C.F.; Chen, S.Y.; Chen, J.Y.; Wu Lee, Y.H. Modulation of p53 transcription regulatory activity and post-translational modification by hepatitis C virus core protein. Oncogene 2004, 23, 2472-2483.

43. Lu, W.; Lo, S.Y.; Chen, M.; Wu, K.; Fung, Y.K.; Ou, J.H. Activation of p53 tumor suppressor by hepatitis C virus core protein. Virology 1999, 264, 134-141.

44. Majumder, M.; Ghosh, A.K.; Steele, R.; Ray, R.; Ray, R.B. Hepatitis C virus NS5A physically associates with p53 and regulates p21/waf1 gene expression in a p53-dependent manner. J. Virol. 2001, 75, 1401-1407.

45. Otsuka, M.; Kato, N.; Lan, K.; Yoshida, H.; Kato, J.; Goto, T.; Shiratori, Y.; Omata, M. Hepatitis $\mathrm{C}$ virus core protein enhances p53 function through augmentation of DNA binding affinity and transcriptional ability. J. Biol. Chem. 2000, 275, 34122-34130.

46. Park, C.Y.; Jun, H.J.; Wakita, T.; Cheong, J.H.; Hwang, S.B. Hepatitis C virus nonstructural 4B protein modulates sterol regulatory element-binding protein signaling via the AKT pathway. J. Biol. Chem. 2009, 284, 9237-9246.

47. Gregoire, I.P.; Richetta, C.; Meyniel-Schicklin, L.; Borel, S.; Pradezynski, F.; Diaz, O.; Deloire, A.; Azocar, O.; Baguet, J.; Le Breton, M.; et al. IRGM is a common target of RNA viruses that subvert the autophagy network. PLoS Pathog. 2011, 7, e1002422.

48. Su, W.C.; Chao, T.C.; Huang, Y.L.; Weng, S.C.; Jeng, K.S.; Lai, M.M. Rab5 and class III phosphoinositide 3-kinase Vps34 are involved in hepatitis C virus NS4B-induced autophagy. J. Virol. 2011, 85, 10561-10571.

49. Street, A.; Macdonald, A.; Crowder, K.; Harris, M. The Hepatitis C virus NS5A protein activates a phosphoinositide 3-kinase-dependent survival signaling cascade. J. Biol. Chem. 2004, 279, 12232-12241.

50. He, Y.; Nakao, H.; Tan, S.L.; Polyak, S.J.; Neddermann, P.; Vijaysri, S.; Jacobs, B.L.; Katze, M.G. Subversion of cell signaling pathways by hepatitis $\mathrm{C}$ virus nonstructural 5A protein via interaction with Grb2 and P85 phosphatidylinositol 3-kinase. J. Virol. 2002, 76, 9207-9217. 
51. Tan, S.L.; Nakao, H.; He, Y.; Vijaysri, S.; Neddermann, P.; Jacobs, B.L.; Mayer, B.J.; Katze, M.G. NS5A, a nonstructural protein of hepatitis $\mathrm{C}$ virus, binds growth factor receptor-bound protein 2 adaptor protein in a Src homology 3 domain/ligand-dependent manner and perturbs mitogenic signaling. Proc. Natl. Acad. Sci. U. S. A. 1999, 96, 5533-5538.

52. Gale, M., Jr.; Blakely, C.M.; Kwieciszewski, B.; Tan, S.L.; Dossett, M.; Tang, N.M.; Korth, M.J.; Polyak, S.J.; Gretch, D.R.; Katze, M.G. Control of PKR protein kinase by hepatitis C virus nonstructural 5A protein: Molecular mechanisms of kinase regulation. Mol. Cell Biol. 1998, 18, 5208-5218.

53. Mankouri, J.; Dallas, M.L.; Hughes, M.E.; Griffin, S.D.; Macdonald, A.; Peers, C.; Harris, M. Suppression of a pro-apoptotic $\mathrm{K}+$ channel as a mechanism for hepatitis $\mathrm{C}$ virus persistence. Proc. Natl. Acad. Sci. U. S. A. 2009, 106, 15903-15908.

54. Guevin, C.; Manna, D.; Belanger, C.; Konan, K.V.; Mak, P.; Labonte, P. Autophagy protein ATG5 interacts transiently with the hepatitis C virus RNA polymerase (NS5B) early during infection. Virology 2010, 405, 1-7.

55. Ait-Goughoulte, M.; Kanda, T.; Meyer, K.; Ryerse, J.S.; Ray, R.B.; Ray, R. Hepatitis C virus genotype 1a growth and induction of autophagy. J. Virol. 2008, 82, 2241-2249.

56. Crusius, K.; Rodriguez, I.; Alonso, A. The human papillomavirus type 16 E5 protein modulates ERK1/2 and p38 MAP kinase activation by an EGFR-independent process in stressed human keratinocytes. Virus Genes 2000, 20, 65-69.

57. Sudarshan, S.R.; Schlegel, R.; Liu, X. The HPV-16 E5 protein represses expression of stress pathway genes XBP-1 and COX-2 in genital keratinocytes. Biochem. Biophys. Res. Commun. 2010, 399, 617-622.

58. Lu, Z.; Hu, X.; Li, Y.; Zheng, L.; Zhou, Y.; Jiang, H.; Ning, T.; Basang, Z.; Zhang, C.; Ke, Y. Human papillomavirus 16 E6 oncoprotein interferences with insulin signaling pathway by binding to tuberin. J. Biol. Chem. 2004, 279, 35664-35670.

59. Spangle, J.M.; Munger, K. The human papillomavirus type 16 E6 oncoprotein activates mTORC1 signaling and increases protein synthesis. J. Virol. 2010, 84, 9398-9407.

60. Scheffner, M.; Werness, B.A.; Huibregtse, J.M.; Levine, A.J.; Howley, P.M. The E6 oncoprotein encoded by human papillomavirus types 16 and 18 promotes the degradation of p53. Cell 1990, 63, 1129-1136.

61. Subbaramaiah, K.; Dannenberg, A.J. Cyclooxygenase-2 transcription is regulated by human papillomavirus 16 E6 and E7 oncoproteins: Evidence of a corepressor/coactivator exchange. Cancer Res. 2007, 67, 3976-3985.

62. Menges, C.W.; Baglia, L.A.; Lapoint, R.; McCance, D.J. Human papillomavirus type 16 E7 up-regulates AKT activity through the retinoblastoma protein. Cancer Res. 2006, 66, 5555-5559.

63. Pim, D.; Massimi, P.; Dilworth, S.M.; Banks, L. Activation of the protein kinase B pathway by the HPV-16 E7 oncoprotein occurs through a mechanism involving interaction with PP2A. Oncogene 2005, 24, 7830-7838.

64. Basile, J.R.; Zacny, V.; Munger, K. The cytokines tumor necrosis factor-alpha (TNF-alpha ) and TNF-related apoptosis-inducing ligand differentially modulate proliferation and apoptotic pathways in human keratinocytes expressing the human papillomavirus-16 E7 oncoprotein. J. Biol. Chem. 2001, 276, 22522-22528. 
65. Pietenpol, J.A.; Stein, R.W.; Moran, E.; Yaciuk, P.; Schlegel, R.; Lyons, R.M.; Pittelkow, M.R.; Munger, K.; Howley, P.M.; Moses, H.L. TGF-beta 1 inhibition of c-myc transcription and growth in keratinocytes is abrogated by viral transforming proteins with pRB binding domains. Cell 1990, 61, 777-785.

66. Vandermark, E.R.; Deluca, K.A.; Gardner, C.R.; Marker, D.F.; Schreiner, C.N.; Strickland, D.A.; Wilton, K.M.; Mondal, S.; Woodworth, C.D. Human papillomavirus type 16 E6 and E 7 proteins alter NF-kB in cultured cervical epithelial cells and inhibition of NF-kB promotes cell growth and immortalization. Virology 2012, 425, 53-60.

67. Mileo, A.M.; Abbruzzese, C.; Mattarocci, S.; Bellacchio, E.; Pisano, P.; Federico, A.; Maresca, V.; Picardo, M.; Giorgi, A.; Maras, B.; et al. Human papillomavirus-16 E7 interacts with glutathione S-transferase P1 and enhances its role in cell survival. PLoS One 2009, 4, e 7254.

68. Zhou, X.; Munger, K. Expression of the human papillomavirus type 16 E7 oncoprotein induces an autophagy-related process and sensitizes normal human keratinocytes to cell death in response to growth factor deprivation. Virology 2009, 385, 192-197.

69. Suzuki, S.; Singhirunnusorn, P.; Mori, A.; Yamaoka, S.; Kitajima, I.; Saiki, I.; Sakurai, H. Constitutive activation of TAK1 by HTLV-1 tax-dependent overexpression of TAB2 induces activation of JNK-ATF2 but not IKK-NF-kappaB. J. Biol. Chem. 2007, 282, 25177-25181.

70. Peloponese, J.M., Jr.; Jeang, K.T. Role for Akt/protein kinase B and activator protein-1 in cellular proliferation induced by the human T-cell leukemia virus type 1 tax oncoprotein. J. Biol. Chem. 2006, 281, 8927-8938.

71. Yoshita, M.; Higuchi, M.; Takahashi, M.; Oie, M.; Tanaka, Y.; Fujii, M. Activation of mTOR by human T-cell leukemia virus type 1 Tax is important for the transformation of mouse $\mathrm{T}$ cells to interleukin-2-independent growth. Cancer Sci. 2011, 103, 369-374.

72. Ku, S.C.; Lee, J.; Lau, J.; Gurumurthy, M.; Ng, R.; Lwa, S.H.; Lee, J.; Klase, Z.; Kashanchi, F.; Chao, S.H. XBP-1, a novel human T-lymphotropic virus type 1 (HTLV-1) tax binding protein, activates HTLV-1 basal and tax-activated transcription. J. Virol. 2008, 82, 4343-4353.

73. Jeong, S.J.; Radonovich, M.; Brady, J.N.; Pise-Masison, C.A. HTLV-I Tax induces a novel interaction between p65/RelA and p53 that results in inhibition of p53 transcriptional activity. Blood 2004, 104, 1490-1497.

74. Geleziunas, R.; Ferrell, S.; Lin, X.; Mu, Y.; Cunningham, E.T., Jr.; Grant, M.; Connelly, M.A.; Hambor, J.E.; Marcu, K.B.; Greene, W.C. Human T-cell leukemia virus type 1 Tax induction of NF-kappaB involves activation of the IkappaB kinase alpha (IKKalpha) and IKKbeta cellular kinases. Mol. Cell Biol. 1998, 18, 5157-5165.

75. Shuda, M.; Kwun, H.J.; Feng, H.; Chang, Y.; Moore, P.S. Human Merkel cell polyomavirus small $\mathrm{T}$ antigen is an oncoprotein targeting the 4E-BP1 translation regulator. J. Clin. Invest. 2011, 121, 3623-3634.

76. Uhlik, M.; Good, L.; Xiao, G.; Harhaj, E.W.; Zandi, E.; Karin, M.; Sun, S.C. NF-kappaBinducing kinase and IkappaB kinase participate in human T-cell leukemia virus I Tax-mediated NF-kappaB activation. J. Biol. Chem. 1998, 273, 21132-21136.

77. Zhao, T.; Yasunaga, J.; Satou, Y.; Nakao, M.; Takahashi, M.; Fujii, M.; Matsuoka, M. Human T-cell leukemia virus type 1 bZIP factor selectively suppresses the classical pathway of NF-kappaB. Blood 2009, 113, 2755-2764. 
78. Tomlinson, C.C.; Damania, B. The K1 protein of Kaposi's sarcoma-associated herpesvirus activates the Akt signaling pathway. J. Virol. 2004, 78, 1918-1927.

79. Wang, L.; Damania, B. Kaposi's sarcoma-associated herpesvirus confers a survival advantage to endothelial cells. Cancer Res. 2008, 68, 4640-4648.

80. Wang, L.; Dittmer, D.P.; Tomlinson, C.C.; Fakhari, F.D.; Damania, B. Immortalization of primary endothelial cells by the $\mathrm{K} 1$ protein of Kaposi's sarcoma-associated herpesvirus. Cancer Res. 2006, 66, 3658-3666.

81. Brinkmann, M.M.; Glenn, M.; Rainbow, L.; Kieser, A.; Henke-Gendo, C.; Schulz, T.F. Activation of mitogen-activated protein kinase and NF-kappaB pathways by a Kaposi's sarcomaassociated herpesvirus K15 membrane protein. J. Virol. 2003, 77, 9346-9358.

82. Friborg, J., Jr.; Kong, W.; Hottiger, M.O.; Nabel, G.J. p53 inhibition by the LANA protein of KSHV protects against cell death. Nature 1999, 402, 889-894.

83. Kuang, E.; Fu, B.; Liang, Q.; Myoung, J.; Zhu, F. Phosphorylation of eukaryotic translation initiation factor 4B (EIF4B) by open reading frame 45/p90 ribosomal S6 kinase (ORF45/RSK) signaling axis facilitates protein translation during Kaposi sarcoma-associated herpesvirus (KSHV) lytic replication. J. Biol. Chem. 2011, 286, 41171-41182.

84. Kuang, E.; Tang, Q.; Maul, G.G.; Zhu, F. Activation of p90 ribosomal S6 kinase by ORF45 of Kaposi's sarcoma-associated herpesvirus and its role in viral lytic replication. J. Virol. 2008, 82, $1838-1850$.

85. Gonzalez, C.M.; Wong, E.L.; Bowser, B.S.; Hong, G.K.; Kenney, S.; Damania, B. Identification and characterization of the Orf49 protein of Kaposi's sarcoma-associated herpesvirus. J. Virol. 2006, 80, 3062-3070.

86. Bais, C.; Santomasso, B.; Coso, O.; Arvanitakis, L.; Raaka, E.G.; Gutkind, J.S.; Asch, A.S.; Cesarman, E.; Gershengorn, M.C.; Mesri, E.A. G-protein-coupled receptor of Kaposi's sarcomaassociated herpesvirus is a viral oncogene and angiogenesis activator. Nature 1998, 391, 86-89.

87. Wen, H.J.; Yang, Z.; Zhou, Y.; Wood, C. Enhancement of autophagy during lytic replication by the Kaposi's sarcoma-associated herpesvirus replication and transcription activator. J. Virol. 2010, 84, 7448-7458.

88. Liang, X.H.; Kleeman, L.K.; Jiang, H.H.; Gordon, G.; Goldman, J.E.; Berry, G.; Herman, B.; Levine, B. Protection against fatal Sindbis virus encephalitis by beclin, a novel Bcl-2-interacting protein. J. Virol. 1998, 72, 8586-8596.

89. Pattingre, S.; Tassa, A.; Qu, X.; Garuti, R.; Liang, X.H.; Mizushima, N.; Packer, M.; Schneider, M.D.; Levine, B. Bcl-2 antiapoptotic proteins inhibit Beclin 1-dependent autophagy. Cell 2005, 122, 927-939.

90. Lee, J.S.; Li, Q.; Lee, J.Y.; Lee, S.H.; Jeong, J.H.; Lee, H.R.; Chang, H.; Zhou, F.C.; Gao, S.J.; Liang, C.; et al. FLIP-mediated autophagy regulation in cell death control. Nat. Cell Biol. 2009, $11,1355-1362$.

91. Cannon, M.L.; Cesarman, E. The KSHV G protein-coupled receptor signals via multiple pathways to induce transcription factor activation in primary effusion lymphoma cells. Oncogene 2004, 23, 514-523.

92. Guasparri, I.; Keller, S.A.; Cesarman, E. KSHV vFLIP is essential for the survival of infected lymphoma cells. J. Exp. Med. 2004, 199, 993-1003. 
93. Konrad, A.; Wies, E.; Thurau, M.; Marquardt, G.; Naschberger, E.; Hentschel, S.; Jochmann, R.; Schulz, T.F.; Erfle, H.; Brors, B.; et al. A systems biology approach to identify the combination effects of human herpesvirus 8 genes on NF-kappaB activation. J. Virol. 2009, 83, 2563-2574.

94. Lei, X.; Bai, Z.; Ye, F.; Xie, J.; Kim, C.G.; Huang, Y.; Gao, S.J. Regulation of NF-kappaB inhibitor IkappaBalpha and viral replication by a KSHV microRNA. Nat. Cell Biol. 2010, 12, 193-199.

95. Martin, D.; Galisteo, R.; Ji, Y.; Montaner, S.; Gutkind, J.S. An NF-kappaB gene expression signature contributes to Kaposi's sarcoma virus vGPCR-induced direct and paracrine neoplasia. Oncogene 2008, 27, 1844-1852.

96. Seo, T.; Park, J.; Lim, C.; Choe, J. Inhibition of nuclear factor kappaB activity by viral interferon regulatory factor 3 of Kaposi's sarcoma-associated herpesvirus. Oncogene 2004, 23, 6146-6155.

97. Martin, D.; Galisteo, R.; Molinolo, A.A.; Wetzker, R.; Hirsch, E.; Gutkind, J.S. PI3Kgamma mediates kaposi's sarcoma-associated herpesvirus vGPCR-induced sarcomagenesis. Cancer Cell 2011, 19, 805-813.

98. Burysek, L.; Pitha, P.M. Latently expressed human herpesvirus 8-encoded interferon regulatory factor 2 inhibits double-stranded RNA-activated protein kinase. J. Virol. 2001, 75, 2345-2352.

99. Esteban, M.; Garcia, M.A.; Domingo-Gil, E.; Arroyo, J.; Nombela, C.; Rivas, C. The latency protein LANA2 from Kaposi's sarcoma-associated herpesvirus inhibits apoptosis induced by dsRNA-activated protein kinase but not RNase L activation. J. Gen. Virol. 2003, 84, 1463-1470.

100. Lee, B.S.; Paulose-Murphy, M.; Chung, Y.H.; Connlole, M.; Zeichner, S.; Jung, J.U. Suppression of tetradecanoyl phorbol acetate-induced lytic reactivation of Kaposi's sarcomaassociated herpesvirus by K1 signal transduction. J. Virol. 2002, 76, 12185-12199.

101. Klionsky, D.J.; Abeliovich, H.; Agostinis, P.; Agrawal, D.K.; Aliev, G.; Askew, D.S.; Baba, M.; Baehrecke, E.H.; Bahr, B.A.; Ballabio, A.; et al. Guidelines for the use and interpretation of assays for monitoring autophagy in higher eukaryotes. Autophagy 2012, 8, in press.

102. Webber, J.L.; Tooze, S.A. Coordinated regulation of autophagy by p38alpha MAPK through mAtg9 and p38IP. EMBO J. 2010, 29, 27-40.

103. Wei, Y.; Pattingre, S.; Sinha, S.; Bassik, M.; Levine, B. JNK1-mediated phosphorylation of Bcl2 regulates starvation-induced autophagy. Mol. Cell 2008, 30, 678-688.

104. Zoncu, R.; Efeyan, A.; Sabatini, D.M. mTOR: From growth signal integration to cancer, diabetes and ageing. Nat. Rev. Mol. Cell Biol. 2011, 12, 21-35.

105. Mizushima, N.; Levine, B.; Cuervo, A.M.; Klionsky, D.J. Autophagy fights disease through cellular self-digestion. Nature 2008, 451, 1069-1075.

106. Shen, S.; Kepp, O.; Kroemer, G. The end of autophagic cell death? Autophagy 2012, 8, 1-3.

107. He, C.; Klionsky, D.J. Regulation mechanisms and signaling pathways of autophagy. Annu. Rev. Genet. 2009, 43, 67-93.

108. Nakatogawa, H.; Suzuki, K.; Kamada, Y.; Ohsumi, Y. Dynamics and diversity in autophagy mechanisms: Lessons from yeast. Nat. Rev. Mol. Cell Biol. 2009, 10, 458-467.

109. Okamoto, K.; Kondo-Okamoto, N.; Ohsumi, Y. Mitochondria-anchored receptor Atg32 mediates degradation of mitochondria via selective autophagy. Dev. Cell 2009, 17, 87-97. 
110. Kanki, T.; Wang, K.; Baba, M.; Bartholomew, C.R.; Lynch-Day, M.A.; Du, Z.; Geng, J.; Mao, K.; Yang, Z.; Yen, W.L.; et al. A genomic screen for yeast mutants defective in selective mitochondria autophagy. Mol. Biol. Cell 2009, 20, 4730-4738.

111. Suzuki, K.; Kondo, C.; Morimoto, M.; Ohsumi, Y. Selective transport of alpha-mannosidase by autophagic pathways: Identification of a novel receptor, Atg34p. J. Biol. Chem. 2010, 285, 30019-30025.

112. Nazarko, V.Y.; Nazarko, T.Y.; Farre, J.C.; Stasyk, O.V.; Warnecke, D.; Ulaszewski, S.; Cregg, J.M.; Sibirny, A.A.; Subramani, S. Atg35, a micropexophagy-specific protein that regulates micropexophagic apparatus formation in Pichia pastoris. Autophagy 2011, 7, 375-385.

113. Meijer, W.H.; van der Klei, I.J.; Veenhuis, M.; Kiel, J.A. ATG genes involved in non-selective autophagy are conserved from yeast to man, but the selective Cvt and pexophagy pathways also require organism-specific genes. Autophagy 2007, 3, 106-116.

114. Hosokawa, N.; Sasaki, T.; Iemura, S.; Natsume, T.; Hara, T.; Mizushima, N. Atg101, a novel mammalian autophagy protein interacting with Atg13. Autophagy 2009, 5, 973-979.

115. Fimia, G.M.; Stoykova, A.; Romagnoli, A.; Giunta, L.; Di Bartolomeo, S.; Nardacci, R.; Corazzari, M.; Fuoco, C.; Ucar, A.; Schwartz, P.; et al. Ambra1 regulates autophagy and development of the nervous system. Nature 2007, 447, 1121-1125.

116. Mizushima, N. The role of the Atg1/ULK1 complex in autophagy regulation. Curr. Opin. Cell Biol. 2010, 22, 132-139.

117. Yang, Z.; Klionsky, D.J. Mammalian autophagy: Core molecular machinery and signaling regulation. Curr. Opin. Cell Biol. 2010, 22, 124-131.

118. He, C.; Levine, B. The Beclin 1 interactome. Curr. Opin. Cell Biol. 2010, 22, 140-149.

119. Johansen, T.; Lamark, T. Selective autophagy mediated by autophagic adapter proteins. Autophagy 2011, 7, 279-296.

120. Orvedahl, A.; MacPherson, S.; Sumpter, R., Jr.; Talloczy, Z.; Zou, Z.; Levine, B. Autophagy protects against Sindbis virus infection of the central nervous system. Cell Host Microbe 2010, 7 , $115-127$.

121. Levine, B.; Mizushima, N.; Virgin, H.W. Autophagy in immunity and inflammation. Nature 2011, 469, 323-335.

122. Zhao, Z.; Fux, B.; Goodwin, M.; Dunay, I.R.; Strong, D.; Miller, B.C.; Cadwell, K.; Delgado, M.A.; Ponpuak, M.; Green, K.G.; et al. Autophagosome-independent essential function for the autophagy protein Atg5 in cellular immunity to intracellular pathogens. Cell Host Microbe 2008, 4, 458-469.

123. Levine, B. Eating oneself and uninvited guests: Autophagy-related pathways in cellular defense. Cell 2005, 120, 159-162.

124. Valencia, S.M.; Hutt-Fletcher, L.M. Important but differential roles for actin in trafficking of Epstein-Barr virus in B cells and epithelial cells. J. Virol. 2012, 86, 2-10.

125. Paludan, C.; Schmid, D.; Landthaler, M.; Vockerodt, M.; Kube, D.; Tuschl, T.; Munz, C. Endogenous MHC class II processing of a viral nuclear antigen after autophagy. Science 2005, 307, 593-596. 
126. Schmid, D.; Pypaert, M.; Munz, C. Antigen-loading compartments for major histocompatibility complex class II molecules continuously receive input from autophagosomes. Immunity 2007, 26, 79-92.

127. Dengjel, J.; Schoor, O.; Fischer, R.; Reich, M.; Kraus, M.; Muller, M.; Kreymborg, K.; Altenberend, F.; Brandenburg, J.; Kalbacher, H.; et al. Autophagy promotes MHC class II presentation of peptides from intracellular source proteins. Proc. Natl. Acad. Sci. U. S. A. 2005, 102, 7922-7927.

128. Leung, C.S.; Haigh, T.A.; Mackay, L.K.; Rickinson, A.B.; Taylor, G.S. Nuclear location of an endogenously expressed antigen, EBNA1, restricts access to macroautophagy and the range of CD4 epitope display. Proc. Natl. Acad. Sci. U. S. A. 2010, 107, 2165-2170.

129. Lee, H.K.; Mattei, L.M.; Steinberg, B.E.; Alberts, P.; Lee, Y.H.; Chervonsky, A.; Mizushima, N.; Grinstein, S.; Iwasaki, A. In vivo requirement for Atg5 in antigen presentation by dendritic cells. Immunity 2010, 32, 227-239.

130. English, L.; Chemali, M.; Duron, J.; Rondeau, C.; Laplante, A.; Gingras, D.; Alexander, D.; Leib, D.; Norbury, C.; Lippe, R.; et al. Autophagy enhances the presentation of endogenous viral antigens on MHC class I molecules during HSV-1 infection. Nat. Immunol. 2009, 10, 480-487.

131. Lee, H.K.; Lund, J.M.; Ramanathan, B.; Mizushima, N.; Iwasaki, A. Autophagy-dependent viral recognition by plasmacytoid dendritic cells. Science 2007, 315, 1398-1401.

132. Delgado, M.A.; Elmaoued, R.A.; Davis, A.S.; Kyei, G.; Deretic, V. Toll-like receptors control autophagy. EMBO J. 2008, 27, 1110-1121.

133. Shi, C.S.; Kehrl, J.H. MyD88 and Trif target Beclin 1 to trigger autophagy in macrophages. J. Biol. Chem. 2008, 283, 33175-33182.

134. Chang, S.; Dolganiuc, A.; Szabo, G. Toll-like receptors 1 and 6 are involved in TLR2-mediated macrophage activation by hepatitis C virus core and NS3 proteins. J. Leukoc. Biol. 2007, 82, 479-487.

135. Martin, H.J.; Lee, J.M.; Walls, D.; Hayward, S.D. Manipulation of the toll-like receptor 7 signaling pathway by Epstein-Barr virus. J. Virol. 2007, 81, 9748-9758.

136. Mizobe, T.; Tsukada, J.; Higashi, T.; Mouri, F.; Matsuura, A.; Tanikawa, R.; Minami, Y.; Yoshida, Y.; Tanaka, Y. Constitutive association of MyD88 to IRAK in HTLV-I-transformed T cells. Exp. Hematol. 2007, 35, 1812-1822.

137. West, J.; Damania, B. Upregulation of the TLR3 pathway by Kaposi's sarcoma-associated herpesvirus during primary infection. J. Virol. 2008, 82, 5440-5449.

138. Balachandran, S.; Barber, G.N. PKR in innate immunity, cancer, and viral oncolysis. Methods Mol. Biol. 2007, 383, 277-301.

139. Kroemer, G.; Marino, G.; Levine, B. Autophagy and the integrated stress response. Mol. Cell 2010, 40, 280-293.

140. Talloczy, Z.; Jiang, W.; Virgin, H.W.t.; Leib, D.A.; Scheuner, D.; Kaufman, R.J.; Eskelinen, E.L.; Levine, B. Regulation of starvation- and virus-induced autophagy by the eIF2alpha kinase signaling pathway. Proc. Natl. Acad. Sci. U. S. A. 2002, 99, 190-195.

141. Orvedahl, A.; Levine, B. Viral evasion of autophagy. Autophagy 2008, 4, 280-285.

142. Ke, P.Y.; Chen, S.S. Activation of the unfolded protein response and autophagy after hepatitis C virus infection suppresses innate antiviral immunity in vitro. J. Clin. Invest. 2011, 121, 37-56. 
143. Shrivastava, S.; Raychoudhuri, A.; Steele, R.; Ray, R.; Ray, R.B. Knockdown of autophagy enhances the innate immune response in hepatitis $\mathrm{C}$ virus-infected hepatocytes. Hepatology 2011, 53, 406-414.

144. Estrabaud, E.; De Muynck, S.; Asselah, T. Activation of unfolded protein response and autophagy during $\mathrm{HCV}$ infection modulates innate immune response. J. Hepatol. 2011, 55, $1150-1153$.

145. Taguwa, S.; Kambara, H.; Fujita, N.; Noda, T.; Yoshimori, T.; Koike, K.; Moriishi, K.; Matsuura, Y. Dysfunction of autophagy participates in vacuole formation and cell death in cells replicating hepatitis C virus. J. Virol. 2011, 85, 13185-13194.

146. Sir, D.; Chen, W.L.; Choi, J.; Wakita, T.; Yen, T.S.; Ou, J.H. Induction of incomplete autophagic response by hepatitis $\mathrm{C}$ virus via the unfolded protein response. Hepatology 2008, 48, 10541061.

147. Dreux, M.; Gastaminza, P.; Wieland, S.F.; Chisari, F.V. The autophagy machinery is required to initiate hepatitis C virus replication. Proc. Natl. Acad. Sci. U. S. A. 2009, 106, 14046-14051.

148. Tanida, I.; Fukasawa, M.; Ueno, T.; Kominami, E.; Wakita, T.; Hanada, K. Knockdown of autophagy-related gene decreases the production of infectious hepatitis $\mathrm{C}$ virus particles. Autophagy 2009, 5, 937-945.

149. Gosert, R.; Kanjanahaluethai, A.; Egger, D.; Bienz, K.; Baker, S.C. RNA replication of mouse hepatitis virus takes place at double-membrane vesicles. J. Virol. 2002, 76, 3697-3708.

150. Jackson, W.T.; Giddings, T.H., Jr.; Taylor, M.P.; Mulinyawe, S.; Rabinovitch, M.; Kopito, R.R.; Kirkegaard, K. Subversion of cellular autophagosomal machinery by RNA viruses. PLoS Biol. 2005, 3, e156.

151. Khakpoor, A.; Panyasrivanit, M.; Wikan, N.; Smith, D.R. A role for autophagolysosomes in dengue virus 3 production in HepG2 cells. J. Gen. Virol. 2009, 90, 1093-1103.

152. Panyasrivanit, M.; Khakpoor, A.; Wikan, N.; Smith, D.R. Co-localization of constituents of the dengue virus translation and replication machinery with amphisomes. J. Gen. Virol. 2009, 90, 448-456.

153. Prentice, E.; Jerome, W.G.; Yoshimori, T.; Mizushima, N.; Denison, M.R. Coronavirus replication complex formation utilizes components of cellular autophagy. J. Biol. Chem. 2004, 279, 10136-10141.

154. Sir, D.; Kuo, C.F.; Tian, Y.; Liu, H.M.; Huang, E.J.; Jung, J.U.; Machida, K.; Ou, J.H. Replication of hepatitis C virus RNA on autophagosomal membranes. J. Biol. Chem. 2012, 287, 18036-18043.

155. Tian, Y.; Sir, D.; Kuo, C.F.; Ann, D.K.; Ou, J.H. Autophagy required for hepatitis B virus replication in transgenic mice. J. Virol. 2011, 85, 13453-13456.

156. Vescovo, T.; Romagnoli, A.; Perdomo, A.B.; Corazzari, M.; Ciccosanti, F.; Alonzi, T.; Nardacci, R.; Ippolito, G.; Tripodi, M.; Garcia-Monzon, C.; et al. Autophagy protects cells from HCV-induced defects in lipid metabolism. Gastroenterology 2012, 142, 644-653 e643.

157. Sun, R.; Lin, S.F.; Staskus, K.; Gradoville, L.; Grogan, E.; Haase, A.; Miller, G. Kinetics of Kaposi's sarcoma-associated herpesvirus gene expression. J. Virol. 1999, 73, 2232-2242.

158. Cheng, E.H.; Nicholas, J.; Bellows, D.S.; Hayward, G.S.; Guo, H.G.; Reitz, M.S.; Hardwick, J.M. A Bcl-2 homolog encoded by Kaposi sarcoma-associated virus, human herpesvirus 8, 
inhibits apoptosis but does not heterodimerize with Bax or Bak. Proc. Natl. Acad. Sci. U. S. A. 1997, 94, 690-694.

159. Sarid, R.; Sato, T.; Bohenzky, R.A.; Russo, J.J.; Chang, Y. Kaposi's sarcoma-associated herpesvirus encodes a functional bcl-2 homologue. Nat. Med. 1997, 3, $293-298$.

160. Virgin, H.W.t.; Latreille, P.; Wamsley, P.; Hallsworth, K.; Weck, K.E.; Dal Canto, A.J.; Speck, S.H. Complete sequence and genomic analysis of murine gammaherpesvirus 68. J. Virol. 1997, 71, 5894-5904.

161. Liang, C.; E, X.; Jung, J.U. Downregulation of autophagy by herpesvirus Bcl-2 homologs. Autophagy 2008, 4, 268-272.

162. Pearson, G.R.; Luka, J.; Petti, L.; Sample, J.; Birkenbach, M.; Braun, D.; Kieff, E. Identification of an Epstein-Barr virus early gene encoding a second component of the restricted early antigen complex. Virology 1987, 160, 151-161.

163. Marshall, W.L.; Yim, C.; Gustafson, E.; Graf, T.; Sage, D.R.; Hanify, K.; Williams, L.; Fingeroth, J.; Finberg, R.W. Epstein-Barr virus encodes a novel homolog of the bcl-2 oncogene that inhibits apoptosis and associates with Bax and Bak. J. Virol. 1999, 73, 5181-5185.

164. Chou, J.; Kern, E.R.; Whitley, R.J.; Roizman, B. Mapping of herpes simplex virus-1 neurovirulence to gamma 134.5, a gene nonessential for growth in culture. Science 1990, 250, 1262-1266.

165. Kyei, G.B.; Dinkins, C.; Davis, A.S.; Roberts, E.; Singh, S.B.; Dong, C.; Wu, L.; Kominami, E.; Ueno, T.; Yamamoto, A.; et al. Autophagy pathway intersects with HIV-1 biosynthesis and regulates viral yields in macrophages. J. Cell Biol. 2009, 186, 255-268.

166. Gannage, M.; Dormann, D.; Albrecht, R.; Dengjel, J.; Torossi, T.; Ramer, P.C.; Lee, M.; Strowig, T.; Arrey, F.; Conenello, G.; et al. Matrix protein 2 of influenza A virus blocks autophagosome fusion with lysosomes. Cell Host Microbe 2009, 6, 367-380.

167. Orvedahl, A.; Alexander, D.; Talloczy, Z.; Sun, Q.; Wei, Y.; Zhang, W.; Burns, D.; Leib, D.A.; Levine, B. HSV-1 ICP34.5 confers neurovirulence by targeting the Beclin 1 autophagy protein. Cell Host Microbe 2007, 1, 23-35.

168. Irmler, M.; Thome, M.; Hahne, M.; Schneider, P.; Hofmann, K.; Steiner, V.; Bodmer, J.L.; Schroter, M.; Burns, K.; Mattmann, C.; et al. Inhibition of death receptor signals by cellular FLIP. Nature 1997, 388, 190-195.

169. Thome, M.; Schneider, P.; Hofmann, K.; Fickenscher, H.; Meinl, E.; Neipel, F.; Mattmann, C.; Burns, K.; Bodmer, J.L.; Schroter, M.; et al. Viral FLICE-inhibitory proteins (FLIPs) prevent apoptosis induced by death receptors. Nature 1997, 386, 517-521.

170. Singh, S.B.; Davis, A.S.; Taylor, G.A.; Deretic, V. Human IRGM induces autophagy to eliminate intracellular mycobacteria. Science 2006, 313, 1438-1441.

171. Manning, B.D.; Cantley, L.C. AKT/PKB signaling: Navigating downstream. Cell 2007, 129, 1261-1274.

172. Noda, T.; Ohsumi, Y. Tor, a phosphatidylinositol kinase homologue, controls autophagy in yeast. J. Biol. Chem. 1998, 273, 3963-3966.

173. Dazert, E.; Hall, M.N. mTOR signaling in disease. Curr. Opin. Cell Biol. 2011, 23, 744-755.

174. Yuan, T.L.; Cantley, L.C. PI3K pathway alterations in cancer: Variations on a theme. Oncogene 2008, 27, 5497-5510. 
175. Cen, O.; Longnecker, R. Rapamycin reverses splenomegaly and inhibits tumor development in a transgenic model of Epstein-Barr virus-related Burkitt's lymphoma. Mol. Cancer Ther. 2011, 10, 679-686.

176. Nichols, L.A.; Adang, L.A.; Kedes, D.H. Rapamycin blocks production of KSHV/HHV8: Insights into the anti-tumor activity of an immunosuppressant drug. PLoS One 2011, 6, e14535.

177. Stallone, G.; Schena, A.; Infante, B.; Di Paolo, S.; Loverre, A.; Maggio, G.; Ranieri, E.; Gesualdo, L.; Schena, F.P.; Grandaliano, G. Sirolimus for Kaposi's sarcoma in renal-transplant recipients. N. Engl. J. Med. 2005, 352, 1317-1323.

178. Severi, T.; van Malenstein, H.; Verslype, C.; van Pelt, J.F. Tumor initiation and progression in hepatocellular carcinoma: Risk factors, classification, and therapeutic targets. Acta Pharmacol. Sin. 2010, 31, 1409-1420.

179. Wagner, D.; Kniepeiss, D.; Schaffellner, S.; Jakoby, E.; Mueller, H.; Fahrleitner-Pammer, A.; Stiegler, P.; Tscheliessnigg, K.H.; Iberer, F. Sirolimus has a potential to influent viral recurrence in HCV positive liver transplant candidates. Int. Immunopharmacol. 2010, 10, 990-993.

180. Stelzer, M.K.; Pitot, H.C.; Liem, A.; Lee, D.; Kennedy, G.D.; Lambert, P.F. Rapamycin inhibits anal carcinogenesis in two preclinical animal models. Cancer Prev. Res. (Phila) 2010, 3, 1542-1551.

181. Darwiche, N.; Sinjab, A.; Abou-Lteif, G.; Chedid, M.B.; Hermine, O.; Dbaibo, G.; Bazarbachi, A. Inhibition of mammalian target of rapamycin signaling by everolimus induces senescence in adult T-cell leukemia/lymphoma and apoptosis in peripheral T-cell lymphomas. Int. J. Cancer 2011, 129, 993-1004.

182. Ikezoe, T.; Nishioka, C.; Bandobashi, K.; Yang, Y.; Kuwayama, Y.; Adachi, Y.; Takeuchi, T.; Koeffler, H.P.; Taguchi, H. Longitudinal inhibition of PI3K/Akt/mTOR signaling by LY294002 and rapamycin induces growth arrest of adult T-cell leukemia cells. Leuk. Res. 2007, 31, 673682.

183. Gires, O.; Zimber-Strobl, U.; Gonnella, R.; Ueffing, M.; Marschall, G.; Zeidler, R.; Pich, D.; Hammerschmidt, W. Latent membrane protein 1 of Epstein-Barr virus mimics a constitutively active receptor molecule. EMBO J. 1997, 16, 6131-6140.

184. Kaye, K.M.; Izumi, K.M.; Kieff, E. Epstein-Barr virus latent membrane protein 1 is essential for B-lymphocyte growth transformation. Proc. Natl. Acad. Sci. U. S. A. 1993, 90, 9150-9154.

185. Wang, D.; Liebowitz, D.; Kieff, E. An EBV membrane protein expressed in immortalized lymphocytes transforms established rodent cells. Cell 1985, 43, 831-840.

186. Kulwichit, W.; Edwards, R.H.; Davenport, E.M.; Baskar, J.F.; Godfrey, V.; Raab-Traub, N. Expression of the Epstein-Barr virus latent membrane protein 1 induces B cell lymphoma in transgenic mice. Proc. Natl. Acad. Sci. U. S. A. 1998, 95, 11963-11968.

187. Longnecker, R.; Kieff, E. A second Epstein-Barr virus membrane protein (LMP2) is expressed in latent infection and colocalizes with LMP1. J. Virol. 1990, 64, 2319-2326.

188. Speck, P.; Kline, K.A.; Cheresh, P.; Longnecker, R. Epstein-Barr virus lacking latent membrane protein 2 immortalizes B cells with efficiency indistinguishable from that of wild-type virus. J. Gen. Virol. 1999, 80, 2193-2203. 
189. Shair, K.H.; Bendt, K.M.; Edwards, R.H.; Nielsen, J.N.; Moore, D.T.; Raab-Traub, N. EpsteinBarr virus encoded LMP1 and LMP2A function co-operatively to promote carcinoma development in a mouse carcinogenesis model. J. Virol. 2012, 86, 5352-5365.

190. Portis, T.; Longnecker, R. Epstein-Barr virus (EBV) LMP2A mediates B-lymphocyte survival through constitutive activation of the Ras/PI3K/Akt pathway. Oncogene 2004, 23, 8619-8628.

191. Burkhardt, A.L.; Bolen, J.B.; Kieff, E.; Longnecker, R. An Epstein-Barr virus transformationassociated membrane protein interacts with src family tyrosine kinases. J. Virol. 1992, 66, 5161-5167.

192. Miller, C.L.; Lee, J.H.; Kieff, E.; Longnecker, R. An integral membrane protein (LMP2) blocks reactivation of Epstein-Barr virus from latency following surface immunoglobulin crosslinking. Proc. Natl. Acad. Sci. U. S. A. 1994, 91, 772-776.

193. Panousis, C.G.; Rowe, D.T. Epstein-Barr virus latent membrane protein 2 associates with and is a substrate for mitogen-activated protein kinase. J. Virol. 1997, 71, 4752-4760.

194. Rommel, C.; Camps, M.; Ji, H. PI3K delta and PI3K gamma: Partners in crime in inflammation in rheumatoid arthritis and beyond? Nat. Rev. Immunol. 2007, 7, 191-201.

195. Sodhi, A.; Chaisuparat, R.; Hu, J.; Ramsdell, A.K.; Manning, B.D.; Sausville, E.A.; Sawai, E.T.; Molinolo, A.; Gutkind, J.S.; Montaner, S. The TSC2/mTOR pathway drives endothelial cell transformation induced by the Kaposi's sarcoma-associated herpesvirus G protein-coupled receptor. Cancer Cell 2006, 10, 133-143.

196. Lee, H.; Guo, J.; Li, M.; Choi, J.K.; DeMaria, M.; Rosenzweig, M.; Jung, J.U. Identification of an immunoreceptor tyrosine-based activation motif of K1 transforming protein of Kaposi's sarcoma-associated herpesvirus. Mol. Cell Biol. 1998, 18, 5219-5228.

197. Lagunoff, M.; Majeti, R.; Weiss, A.; Ganem, D. Deregulated signal transduction by the K1 gene product of Kaposi's sarcoma-associated herpesvirus. Proc. Natl. Acad. Sci. U. S. A. 1999, 96, 5704-5709.

198. Lee, B.S.; Connole, M.; Tang, Z.; Harris, N.L.; Jung, J.U. Structural analysis of the Kaposi's sarcoma-associated herpesvirus K1 protein. J. Virol. 2003, 77, 8072-8086.

199. Cross, J.C.; Wen, P.; Rutter, W.J. Transactivation by hepatitis B virus X protein is promiscuous and dependent on mitogen-activated cellular serine/threonine kinases. Proc. Natl. Acad. Sci. U. S. A. 1993, 90, 8078-8082.

200. Peng, L.; Liang, D.; Tong, W.; Li, J.; Yuan, Z. Hepatitis C virus NS5A activates the mammalian target of rapamycin (mTOR) pathway, contributing to cell survival by disrupting the interaction between FK506-binding protein 38 (FKBP38) and mTOR. J. Biol. Chem. 2010, 285, 2087020881.

201. Guo, H.; Zhou, T.; Jiang, D.; Cuconati, A.; Xiao, G.H.; Block, T.M.; Guo, J.T. Regulation of hepatitis $\mathrm{B}$ virus replication by the phosphatidylinositol 3-kinase-akt signal transduction pathway. J. Virol. 2007, 81, 10072-10080.

202. Mannova, P.; Beretta, L. Activation of the N-Ras-PI3K-Akt-mTOR pathway by hepatitis C virus: Control of cell survival and viral replication. J. Virol. 2005, 79, 8742-8749.

203. Ishida, H.; Li, K.; Yi, M.; Lemon, S.M. p21-activated kinase 1 is activated through the mammalian target of rapamycin/p70 S6 kinase pathway and regulates the replication of hepatitis C virus in human hepatoma cells. J. Biol. Chem. 2007, 282, 11836-11848. 
204. Shao, R.X.; Zhang, L.; Peng, L.F.; Sun, E.; Chung, W.J.; Jang, J.Y.; Tsai, W.L.; Hyppolite, G.; Chung, R.T. Suppressor of cytokine signaling 3 suppresses hepatitis C virus replication in an mTOR-dependent manner. J. Virol. 2010, 84, 6060-6069.

205. George, A.; Panda, S.; Kudmulwar, D.; Chhatbar, S.P.; Nayak, S.C.; Krishnan, H.H. Hepatitis C Virus NS5A Binds to the mRNA Cap-binding Eukaryotic Translation Initiation 4F (eIF4F) Complex and Up-regulates Host Translation Initiation Machinery through eIF4E-binding Protein 1 Inactivation. J. Biol. Chem. 2012, 287, 5042-5058.

206. Coito, C.; Diamond, D.L.; Neddermann, P.; Korth, M.J.; Katze, M.G. High-throughput screening of the yeast kinome: Identification of human serine/threonine protein kinases that phosphorylate the hepatitis C virus NS5A protein. J. Virol. 2004, 78, 3502-3513.

207. Zheng, L.; Ding, H.; Lu, Z.; Li, Y.; Pan, Y.; Ning, T.; Ke, Y. E3 ubiquitin ligase E6AP-mediated TSC2 turnover in the presence and absence of HPV16 E6. Genes Cells 2008, 13, 285-294.

208. Zhou, X.; Spangle, J.M.; Munger, K. Expression of a viral oncoprotein in normal human epithelial cells triggers an autophagy-related process: Is autophagy an "Achilles' heel" of human cancers? Autophagy 2009, 5, 578-579.

209. Zwerschke, W.; Mazurek, S.; Massimi, P.; Banks, L.; Eigenbrodt, E.; Jansen-Durr, P. Modulation of type M2 pyruvate kinase activity by the human papillomavirus type 16 E7 oncoprotein. Proc. Natl. Acad. Sci. U. S. A. 1999, 96, 1291-1296.

210. Nardi, V.; Song, Y.C.; Santamaria-Barria, J.A.; Cosper, A.K.; Lam, Q.; Faber, A.C.; Boland, G.M.; Yeap, B.Y.; Bergethon, K.; Scialabba, V.L.; et al. Activation of PI3K signaling in Merkel cell carcinoma. Clin. Cancer Res. 2012, 18, 1227-1236.

211. Roux, P.P.; Blenis, J. ERK and p38 MAPK-activated protein kinases: A family of protein kinases with diverse biological functions. Microbiol. Mol. Biol. Rev. 2004, 68, 320-344.

212. McCubrey, J.A.; Steelman, L.S.; Chappell, W.H.; Abrams, S.L.; Wong, E.W.; Chang, F.; Lehmann, B.; Terrian, D.M.; Milella, M.; Tafuri, A.; et al. Roles of the Raf/MEK/ERK pathway in cell growth, malignant transformation and drug resistance. Biochim. Biophys. Acta 2007, 1773, 1263-1284.

213. Anjum, R.; Roux, P.P.; Ballif, B.A.; Gygi, S.P.; Blenis, J. The tumor suppressor DAP kinase is a target of RSK-mediated survival signaling. Curr. Biol. 2005, 15, 1762-1767.

214. Zalckvar, E.; Berissi, H.; Mizrachy, L.; Idelchuk, Y.; Koren, I.; Eisenstein, M.; Sabanay, H.; Pinkas-Kramarski, R.; Kimchi, A. DAP-kinase-mediated phosphorylation on the BH3 domain of beclin 1 promotes dissociation of beclin 1 from Bcl-XL and induction of autophagy. EMBO Rep. 2009, 10, 285-292.

215. Zheng, B.; Jeong, J.H.; Asara, J.M.; Yuan, Y.Y.; Granter, S.R.; Chin, L.; Cantley, L.C. Oncogenic B-RAF negatively regulates the tumor suppressor LKB1 to promote melanoma cell proliferation. Mol. Cell 2009, 33, 237-247.

216. Hardie, D.G. AMP-activated protein kinase: An energy sensor that regulates all aspects of cell function. Genes Dev. 2011, 25, 1895-1908.

217. Schouten, G.J.; Vertegaal, A.C.; Whiteside, S.T.; Israel, A.; Toebes, M.; Dorsman, J.C.; van der $\mathrm{Eb}$, A.J.; Zantema, A. IkappaB alpha is a target for the mitogen-activated $90 \mathrm{kDa}$ ribosomal S6 kinase. EMBO J. 1997, 16, 3133-3144. 
218. Zhu, F.X.; Cusano, T.; Yuan, Y. Identification of the immediate-early transcripts of Kaposi's sarcoma-associated herpesvirus. J. Virol. 1999, 73, 5556-5567.

219. Kuang, E.; Wu, F.; Zhu, F. Mechanism of sustained activation of ribosomal S6 kinase (RSK) and ERK by kaposi sarcoma-associated herpesvirus ORF45: Multiprotein complexes retain active phosphorylated ERK AND RSK and protect them from dephosphorylation. J. Biol. Chem. 2009, 284, 13958-13968.

220. Kang-Park, S.; Lee, J.H.; Shin, J.H.; Lee, Y.I. Activation of the IGF-II gene by HBV-X protein requires PKC and p44/p42 map kinase signalings. Biochem. Biophys. Res. Commun. 2001, 283, 303-307.

221. Yun, C.; Cho, H.; Kim, S.J.; Lee, J.H.; Park, S.Y.; Chan, G.K.; Cho, H. Mitotic aberration coupled with centrosome amplification is induced by hepatitis B virus X oncoprotein via the Rasmitogen-activated protein/extracellular signal-regulated kinase-mitogen-activated protein pathway. Mol. Cancer Res. 2004, 2, 159-169.

222. Chung, T.W.; Lee, Y.C.; Kim, C.H. Hepatitis B viral HBx induces matrix metalloproteinase-9 gene expression through activation of ERK and PI-3K/AKT pathways: Involvement of invasive potential. FASEB J. 2004, 18, 1123-1125.

223. Egan, D.F.; Shackelford, D.B.; Mihaylova, M.M.; Gelino, S.; Kohnz, R.A.; Mair, W.; Vasquez, D.S.; Joshi, A.; Gwinn, D.M.; Taylor, R.; et al. Phosphorylation of ULK1 (hATG1) by AMPactivated protein kinase connects energy sensing to mitophagy. Science 2010, 331, 456-461.

224. Kim, J.; Kundu, M.; Viollet, B.; Guan, K.L. AMPK and mTOR regulate autophagy through direct phosphorylation of Ulk1. Nat. Cell Biol. 2011, 13, 132-141.

225. Shang, L.; Chen, S.; Du, F.; Li, S.; Zhao, L.; Wang, X. Nutrient starvation elicits an acute autophagic response mediated by Ulk1 dephosphorylation and its subsequent dissociation from AMPK. Proc. Natl. Acad. Sci. U. S. A. 2011, 108, 4788-4793.

226. Lee, J.W.; Park, S.; Takahashi, Y.; Wang, H.G. The association of AMPK with ULK1 regulates autophagy. PLoS One 2010, 5, e15394.

227. Young, A.R.; Chan, E.Y.; Hu, X.W.; Kochl, R.; Crawshaw, S.G.; High, S.; Hailey, D.W.; Lippincott-Schwartz, J.; Tooze, S.A. Starvation and ULK1-dependent cycling of mammalian Atg9 between the TGN and endosomes. J. Cell Sci. 2006, 119, 3888-3900.

228. Mack, H.I.; Zheng, B.; Asara, J.M.; Thomas, S.M. AMPK-dependent phosphorylation of ULK1 regulates ATG9 localization. Autophagy 2012, 8 , in press.

229. Hayden, M.S.; Ghosh, S. Shared principles in NF-kappaB signaling. Cell 2008, 132, 344-362.

230. Herrero-Martin, G.; Hoyer-Hansen, M.; Garcia-Garcia, C.; Fumarola, C.; Farkas, T.; LopezRivas, A.; Jaattela, M. TAK1 activates AMPK-dependent cytoprotective autophagy in TRAILtreated epithelial cells. EMBO J. 2009, 28, 677-685.

231. Hoyer-Hansen, M.; Bastholm, L.; Szyniarowski, P.; Campanella, M.; Szabadkai, G.; Farkas, T.; Bianchi, K.; Fehrenbacher, N.; Elling, F.; Rizzuto, R.; et al. Control of macroautophagy by calcium, calmodulin-dependent kinase kinase-beta, and Bcl-2. Mol. Cell 2007, 25, 193-205.

232. Liang, J.; Shao, S.H.; Xu, Z.X.; Hennessy, B.; Ding, Z.; Larrea, M.; Kondo, S.; Dumont, D.J.; Gutterman, J.U.; Walker, C.L.; et al. The energy sensing LKB1-AMPK pathway regulates p27(kip1) phosphorylation mediating the decision to enter autophagy or apoptosis. Nat. Cell Biol. 2007, 9, 218-224. 
233. Buzzai, M.; Jones, R.G.; Amaravadi, R.K.; Lum, J.J.; DeBerardinis, R.J.; Zhao, F.; Viollet, B.; Thompson, C.B. Systemic treatment with the antidiabetic drug metformin selectively impairs p53-deficient tumor cell growth. Cancer Res. 2007, 67, 6745-6752.

234. Kumar, S.H.; Rangarajan, A. Simian virus 40 small $\mathrm{T}$ antigen activates AMPK and triggers autophagy to protect cancer cells from nutrient deprivation. J. Virol. 2009, 83, 8565-8574.

235. Sommermann, T.G.; Mack, H.I.; Cahir-McFarland, E. Autophagy prolongs survival after NFkappaB inhibition in B-cell lymphomas. Autophagy 2012, 8, 265-267.

236. Meley, D.; Bauvy, C.; Houben-Weerts, J.H.; Dubbelhuis, P.F.; Helmond, M.T.; Codogno, P.; Meijer, A.J. AMP-activated protein kinase and the regulation of autophagic proteolysis. J. Biol. Chem. 2006, 281, 34870-34879.

237. Mankouri, J.; Harris, M. Viruses and the fuel sensor: The emerging link between AMPK and virus replication. Rev. Med. Virol. 2011, 21, 205-212.

238. Mankouri, J.; Tedbury, P.R.; Gretton, S.; Hughes, M.E.; Griffin, S.D.; Dallas, M.L.; Green, K.A.; Hardie, D.G.; Peers, C.; Harris, M. Enhanced hepatitis C virus genome replication and lipid accumulation mediated by inhibition of AMP-activated protein kinase. Proc. Natl. Acad. Sci. U. S. A. 2011, 107, 11549-11554.

239. Moradpour, D.; Penin, F.; Rice, C.M. Replication of hepatitis C virus. Nat. Rev. Microbiol. 2007, $5,453-463$.

240. Kapadia, S.B.; Chisari, F.V. Hepatitis C virus RNA replication is regulated by host geranylgeranylation and fatty acids. Proc. Natl. Acad. Sci. U. S. A. 2005, 102, 2561-2566.

241. Bernsmeier, C.; Duong, F.H.; Christen, V.; Pugnale, P.; Negro, F.; Terracciano, L.; Heim, M.H. Virus-induced over-expression of protein phosphatase $2 \mathrm{~A}$ inhibits insulin signalling in chronic hepatitis C. J. Hepatol. 2008, 49, 429-440.

242. Bottero, V.; Kerur, N.; Sadagopan, S.; Patel, K.; Sharma-Walia, N.; Chandran, B. Phosphorylation and polyubiquitination of transforming growth factor beta-activated kinase 1 are necessary for activation of NF-kappaB by the Kaposi's sarcoma-associated herpesvirus $G$ protein-coupled receptor. J. Virol. 2011, 85, 1980-1993.

243. Zhou, Y.; Wang, S.; Ma, J.W.; Lei, Z.; Zhu, H.F.; Lei, P.; Yang, Z.S.; Zhang, B.; Yao, X.X.; Shi, C.; et al. Hepatitis B virus protein X-induced expression of the CXC chemokine IP-10 is mediated through activation of NF-kappaB and increases migration of leukocytes. J. Biol. Chem. 2010, 285, 12159-12168.

244. Criollo, A.; Senovilla, L.; Authier, H.; Maiuri, M.C.; Morselli, E.; Vitale, I.; Kepp, O.; Tasdemir, E.; Galluzzi, L.; Shen, S.; et al. The IKK complex contributes to the induction of autophagy. EMBO J. 2010, 29, 619-631.

245. Vousden, K.H.; Ryan, K.M. p53 and metabolism. Nat. Rev. Cancer 2009, 9, 691-700.

246. Crighton, D.; Wilkinson, S.; O'Prey, J.; Syed, N.; Smith, P.; Harrison, P.R.; Gasco, M.; Garrone, O.; Crook, T.; Ryan, K.M. DRAM, a p53-induced modulator of autophagy, is critical for apoptosis. Cell 2006, 126, 121-134.

247. Budanov, A.V.; Karin, M. p53 target genes sestrin1 and sestrin2 connect genotoxic stress and mTOR signaling. Cell 2008, 134, 451-460. 
248. Maiuri, M.C.; Malik, S.A.; Morselli, E.; Kepp, O.; Criollo, A.; Mouchel, P.L.; Carnuccio, R.; Kroemer, G. Stimulation of autophagy by the p53 target gene Sestrin2. Cell Cycle 2009, 8, 1571-1576.

249. Feng, Z.; Hu, W.; de Stanchina, E.; Teresky, A.K.; Jin, S.; Lowe, S.; Levine, A.J. The regulation of AMPK beta1, TSC2, and PTEN expression by p53: Stress, cell and tissue specificity, and the role of these gene products in modulating the IGF-1-AKT-mTOR pathways. Cancer Res 2007, 67, 3043-3053.

250. Bensaad, K.; Tsuruta, A.; Selak, M.A.; Vidal, M.N.; Nakano, K.; Bartrons, R.; Gottlieb, E.; Vousden, K.H. TIGAR, a p53-inducible regulator of glycolysis and apoptosis. Cell 2006, 126, 107-120.

251. Bensaad, K.; Cheung, E.C.; Vousden, K.H. Modulation of intracellular ROS levels by TIGAR controls autophagy. EMBO J. 2009, 28, 3015-3026.

252. Tasdemir, E.; Maiuri, M.C.; Galluzzi, L.; Vitale, I.; Djavaheri-Mergny, M.; D'Amelio, M.; Criollo, A.; Morselli, E.; Zhu, C.; Harper, F.; et al. Regulation of autophagy by cytoplasmic p53. Nat. Cell Biol. 2008, 10, 676-687.

253. Morselli, E.; Shen, S.; Ruckenstuhl, C.; Bauer, M.A.; Marino, G.; Galluzzi, L.; Criollo, A.; Michaud, M.; Maiuri, M.C.; Chano, T.; et al. p53 inhibits autophagy by interacting with the human ortholog of yeast Atg17, RB1CC1/FIP200. Cell Cycle 2011, 10, 2763-2769.

254. Levine, A.J. The common mechanisms of transformation by the small DNA tumor viruses: The inactivation of tumor suppressor gene products: p53. Virology 2009, 384, 285-293.

255. Huibregtse, J.M.; Scheffner, M.; Howley, P.M. A cellular protein mediates association of p53 with the E6 oncoprotein of human papillomavirus types 16 or 18. EMBO J. 1991, 10, 4129-4135.

256. Scheffner, M.; Huibregtse, J.M.; Vierstra, R.D.; Howley, P.M. The HPV-16 E6 and E6-AP complex functions as a ubiquitin-protein ligase in the ubiquitination of p53. Cell 1993, 75, 495-505.

257. Lane, D.P.; Crawford, L.V. T antigen is bound to a host protein in SV40-transformed cells. Nature 1979, 278, 261-263.

258. O'Shea, C.C.; Fried, M. Modulation of the ARF-p53 pathway by the small DNA tumor viruses. Cell Cycle 2005, 4, 449-452.

259. Wang, E.H.; Friedman, P.N.; Prives, C. The murine p53 protein blocks replication of SV40 DNA in vitro by inhibiting the initiation functions of SV40 large T antigen. Cell 1989, 57, 379-392.

260. Qing, G.; Yan, P.; Qu, Z.; Liu, H.; Xiao, G. Hsp90 regulates processing of NF-kappa B2 p100 involving protection of NF-kappa B-inducing kinase (NIK) from autophagy-mediated degradation. Cell Res. 2007, 17, 520-530.

261. Qing, G.; Yan, P.; Xiao, G. Hsp90 inhibition results in autophagy-mediated proteasomeindependent degradation of IkappaB kinase (IKK). Cell Res. 2006, 16, 895-901.

262. Criollo, A.; Chereau, F.; Malik, S.A.; Niso-Santano, M.; Marino, G.; Galluzzi, L.; Maiuri, M.C.; Baud, V.; Kroemer, G. Autophagy is required for the activation of NFkappaB. Cell Cycle 2012, 11, 194-199.

263. Copetti, T.; Bertoli, C.; Dalla, E.; Demarchi, F.; Schneider, C. p65/RelA modulates BECN1 transcription and autophagy. Mol. Cell Biol. 2009, 29, 2594-2608. 
264. Djavaheri-Mergny, M.; Amelotti, M.; Mathieu, J.; Besancon, F.; Bauvy, C.; Souquere, S.; Pierron, G.; Codogno, P. NF-kappaB activation represses tumor necrosis factor-alpha-induced autophagy. J. Biol. Chem. 2006, 281, 30373-30382.

265. Niso-Santano, M.; Criollo, A.; Malik, S.A.; Michaud, M.; Morselli, E.; Marino, G.; Lachkar, S.; Galluzzi, L.; Maiuri, M.C.; Kroemer, G. Direct molecular interactions between Beclin 1 and the canonical NFkappaB activation pathway. Autophagy 2012, 8, 268-270.

266. Chu, Z.L.; Shin, Y.A.; Yang, J.M.; DiDonato, J.A.; Ballard, D.W. IKKgamma mediates the interaction of cellular IkappaB kinases with the tax transforming protein of human $\mathrm{T}$ cell leukemia virus type 1. J. Biol. Chem. 1999, 274, 15297-15300.

267. Field, N.; Low, W.; Daniels, M.; Howell, S.; Daviet, L.; Boshoff, C.; Collins, M. KSHV vFLIP binds to IKK-gamma to activate IKK. J. Cell Sci. 2003, 116, 3721-3728.

268. Harhaj, E.W.; Sun, S.C. IKKgamma serves as a docking subunit of the IkappaB kinase (IKK) and mediates interaction of IKK with the human T-cell leukemia virus Tax protein. J. Biol. Chem. 1999, 274, 22911-22914.

269. Jin, D.Y.; Giordano, V.; Kibler, K.V.; Nakano, H.; Jeang, K.T. Role of adapter function in oncoprotein-mediated activation of NF-kappaB. Human T-cell leukemia virus type I Tax interacts directly with IkappaB kinase gamma. J. Biol. Chem. 1999, 274, 17402-17405.

270. Liu, L.; Eby, M.T.; Rathore, N.; Sinha, S.K.; Kumar, A.; Chaudhary, P.M. The human herpes virus 8-encoded viral FLICE inhibitory protein physically associates with and persistently activates the Ikappa B kinase complex. J. Biol. Chem. 2002, 277, 13745-13751.

271. Matta, H.; Chaudhary, P.M. Activation of alternative NF-kappa B pathway by human herpes virus 8-encoded Fas-associated death domain-like IL-1 beta-converting enzyme inhibitory protein (vFLIP). Proc. Natl. Acad. Sci. U. S. A. 2004, 101, 9399-9404.

272. Matta, H.; Mazzacurati, L.; Schamus, S.; Yang, T.; Sun, Q.; Chaudhary, P.M. Kaposi's sarcoma-associated herpesvirus (KSHV) oncoprotein K13 bypasses TRAFs and directly interacts with the IkappaB kinase complex to selectively activate NF-kappaB without JNK activation. $J$. Biol. Chem. 2007, 282, 24858-24865.

273. Xiao, G.; Cvijic, M.E.; Fong, A.; Harhaj, E.W.; Uhlik, M.T.; Waterfield, M.; Sun, S.C. Retroviral oncoprotein Tax induces processing of NF-kappaB2/p100 in T cells: Evidence for the involvement of IKKalpha. EMBO J. 2001, 20, 6805-6815.

274. de Oliveira, D.E.; Ballon, G.; Cesarman, E. NF-kappaB signaling modulation by EBV and KSHV. Trends Microbiol. 2010, 18, 248-257.

275. Cahir McFarland, E.D.; Izumi, K.M.; Mosialos, G. Epstein-barr virus transformation: Involvement of latent membrane protein 1-mediated activation of NF-kappaB. Oncogene 1999, $18,6959-6964$.

276. Lin, W.; Tsai, W.L.; Shao, R.X.; Wu, G.; Peng, L.F.; Barlow, L.L.; Chung, W.J.; Zhang, L.; Zhao, H.; Jang, J.Y.; et al. Hepatitis C virus regulates transforming growth factor beta1 production through the generation of reactive oxygen species in a nuclear factor kappaB-dependent manner. Gastroenterology 2010, 138, 2509-2518, 2518 e2501.

277. Kiyono, K.; Suzuki, H.I.; Matsuyama, H.; Morishita, Y.; Komuro, A.; Kano, M.R.; Sugimoto, K.; Miyazono, K. Autophagy is activated by TGF-beta and potentiates TGF-beta-mediated growth inhibition in human hepatocellular carcinoma cells. Cancer Res. 2009, 69, 8844-8852. 
278. Yan, P.; Qing, G.; Qu, Z.; Wu, C.C.; Rabson, A.; Xiao, G. Targeting autophagic regulation of NFkappaB in HTLV-I transformed cells by geldanamycin: Implications for therapeutic interventions. Autophagy 2007, 3, 600-603.

279. Ron, D.; Walter, P. Signal integration in the endoplasmic reticulum unfolded protein response. Nat. Rev. Mol. Cell Biol. 2007, 8, 519-529.

280. Walter, P.; Ron, D. The unfolded protein response: From stress pathway to homeostatic regulation. Science 2011, 334, 1081-1086.

281. Izumi, K.M.; Kieff, E.D. The Epstein-Barr virus oncogene product latent membrane protein 1 engages the tumor necrosis factor receptor-associated death domain protein to mediate $\mathrm{B}$ lymphocyte growth transformation and activate NF-kappaB. Proc. Natl. Acad. Sci. USA 1997, 94, 12592-12597.

282. Lam, N.; Sandberg, M.L.; Sugden, B. High physiological levels of LMP1 result in phosphorylation of eIF2 alpha in Epstein-Barr virus-infected cells. J. Virol. 2004, 78, 1657-1664.

283. Lee, D.Y.; Lee, J.; Sugden, B. The unfolded protein response and autophagy: Herpesviruses rule! J. Virol. 2009, 83, 1168-1172.

284. Bernales, S.; McDonald, K.L.; Walter, P. Autophagy counterbalances endoplasmic reticulum expansion during the unfolded protein response. PLoS Biol. 2006, 4, e423.

285. Yorimitsu, T.; Nair, U.; Yang, Z.; Klionsky, D.J. Endoplasmic reticulum stress triggers autophagy. J. Biol. Chem. 2006, 281, 30299-30304.

286. Urano, F.; Wang, X.; Bertolotti, A.; Zhang, Y.; Chung, P.; Harding, H.P.; Ron, D. Coupling of stress in the ER to activation of JNK protein kinases by transmembrane protein kinase IRE1. Science 2000, 287, 664-666.

287. Deng, J.; Lu, P.D.; Zhang, Y.; Scheuner, D.; Kaufman, R.J.; Sonenberg, N.; Harding, H.P.; Ron, D. Translational repression mediates activation of nuclear factor kappa B by phosphorylated translation initiation factor 2. Mol. Cell Biol. 2004, 24, 10161-10168.

288. Jiang, H.Y.; Wek, S.A.; McGrath, B.C.; Scheuner, D.; Kaufman, R.J.; Cavener, D.R.; Wek, R.C. Phosphorylation of the alpha subunit of eukaryotic initiation factor 2 is required for activation of NF-kappaB in response to diverse cellular stresses. Mol. Cell Biol. 2003, 23, 5651-5663.

289. Hetz, C.; Thielen, P.; Matus, S.; Nassif, M.; Court, F.; Kiffin, R.; Martinez, G.; Cuervo, A.M.; Brown, R.H.; Glimcher, L.H. XBP-1 deficiency in the nervous system protects against amyotrophic lateral sclerosis by increasing autophagy. Genes Dev. 2009, 23, 2294-2306.

290. Matus, S.; Nassif, M.; Glimcher, L.H.; Hetz, C. XBP-1 deficiency in the nervous system reveals a homeostatic switch to activate autophagy. Autophagy 2009, 5, 1226-1228.

291. Zheng, Y.; Gao, B.; Ye, L.; Kong, L.; Jing, W.; Yang, X.; Wu, Z.; Ye, L. Hepatitis C virus non-structural protein NS4B can modulate an unfolded protein response. J. Microbiol. 2005, 43, $529-536$.

292. Tardif, K.D.; Mori, K.; Kaufman, R.J.; Siddiqui, A. Hepatitis C virus suppresses the IRE1-XBP1 pathway of the unfolded protein response. J. Biol. Chem. 2004, 279, 17158-17164.

293. McPherson, S.; Powell, E.E.; Barrie, H.D.; Clouston, A.D.; McGuckin, M.; Jonsson, J.R. No evidence of the unfolded protein response in patients with chronic hepatitis $\mathrm{C}$ virus infection. J. Gastroenterol. Hepatol. 2011, 26, 319-327. 
294. Asselah, T.; Bieche, I.; Mansouri, A.; Laurendeau, I.; Cazals-Hatem, D.; Feldmann, G.; Bedossa, P.; Paradis, V.; Martinot-Peignoux, M.; Lebrec, D.; et al. In vivo hepatic endoplasmic reticulum stress in patients with chronic hepatitis C. J. Pathol. 2010, 221, 264-274.

(C) 2012 by the authors; licensee MDPI, Basel, Switzerland. This article is an open access article distributed under the terms and conditions of the Creative Commons Attribution license (http://creativecommons.org/licenses/by/3.0/). 